\title{
Altered Theta Oscillations and Aberrant Cortical Excitatory Activity in the 5XFAD Model of Alzheimer's Disease
}

\author{
Magdalena Elisabeth Siwek, ${ }^{1}$ Ralf Müller, ${ }^{2}$ Christina Henseler, ${ }^{1}$ \\ Astrid Trog, ${ }^{3}$ Andreas Lundt, ${ }^{1}$ Carola Wormuth, ${ }^{1}$ Karl Broich, ${ }^{1}$ \\ Dan Ehninger, ${ }^{4}$ Marco Weiergräber, ${ }^{1}$ and Anna Papazoglou ${ }^{1}$ \\ ${ }^{1}$ Federal Institute for Drugs and Medical Devices (BfArM), Kurt-Georg-Kiesinger-Allee 3, 53175 Bonn, Germany \\ ${ }^{2}$ Department of Psychiatry and Psychotherapy, University of Cologne, Faculty of Medicine, Kerpener Street 62, \\ 50937 Cologne, Germany \\ ${ }^{3}$ Institute of Molecular Psychiatry, University of Bonn, Sigmund-Freud Street 25, 53125 Bonn, Germany \\ ${ }^{4}$ German Center for Neurodegenerative Diseases (DZNE), Ludwig-Erhard-Allee 2, 53175 Bonn, Germany
}

Correspondence should be addressed to Marco Weiergräber; marco.weiergraeber@bfarm.de

Received 30 January 2015; Accepted 18 March 2015

Academic Editor: Michel Baudry

Copyright (c) 2015 Magdalena Elisabeth Siwek et al. This is an open access article distributed under the Creative Commons Attribution License, which permits unrestricted use, distribution, and reproduction in any medium, provided the original work is properly cited.

\begin{abstract}
Alzheimer's disease (AD) is an age-related neurodegenerative disorder characterized by impairment of memory function. The 5XFAD mouse model was analyzed and compared with wild-type (WT) controls for aberrant cortical excitability and hippocampal theta oscillations by using simultaneous video-electroencephalogram (EEG) monitoring. Seizure staging revealed that 5XFAD mice exhibited cortical hyperexcitability whereas controls did not. In addition, 5XFAD mice displayed a significant increase in hippocampal theta activity from the light to dark phase during nonmotor activity. We also observed a reduction in mean theta frequency in 5XFAD mice compared to controls that was again most prominent during nonmotor activity. Transcriptome analysis of hippocampal probes and subsequent qPCR validation revealed an upregulation of Plcd4 that might be indicative of enhanced muscarinic signalling. Our results suggest that 5XFAD mice exhibit altered cortical excitability, hippocampal dysrhythmicity, and potential changes in muscarinic signaling.
\end{abstract}

\section{Introduction}

Alzheimer's disease $(\mathrm{AD})$ is an irreversible, progressive brain disorder slowly destroying learning and memory skills. The histopathology of $\mathrm{AD}$ is characterized by two hallmark lesions, extracellular amyloid- $\beta(\mathrm{A} \beta)$ plaques, and intracellular neurofibrillary tangles (NFTs) composed of hyperphosphorylated tau protein. In addition to the presence of $\mathrm{A} \beta$ plaques and NFTs in the brain, considerable neuron loss is also a prominent feature of $\mathrm{AD}$, the mechanisms of which still remain unclear. Importantly, familial AD (FAD) mutations in genes for amyloid- $\beta$ precursor protein $(\mathrm{A} \beta \mathrm{PP})$, presenilin 1 (PSEN1), and presenilin 2 (PSEN2) implicate $\mathrm{A} \beta$ as an initiating factor in $\mathrm{AD}$ pathogenesis. These FAD mutations increase the release of $A \beta 42$ from $A \beta P P$, the latter being sequentially cleaved by the $\beta$ - and $\gamma$-secretase enzymes to release the $\mathrm{A} \beta$. The latter plays a central role in the pathophysiology of $\mathrm{AD}$ and ultimately leads to neuronal cell loss, for example, in the septum, entorhinal cortex, and hippocampus $[1,2]$, and finally to dementia $[3,4]$.

Transgenic mouse models have proven to be valuable tools in investigating the etiopathogenesis of AD [5-11]. Studies on various $\mathrm{AD}$ mouse models revealed dysregulation of the $\beta$-site APP cleaving enzyme 1 (BACE1) that is responsible for the generation of $A \beta$ plaques [12-14]. Therefore, increased translation of BACE1 leads to enhanced plaque formation and finally to a disruption of neuronal functioning within the hippocampus $[15,16]$. Among different AD models, the 5XFAD model is a most progressive and growth retarded 
model expressing multiple FAD mutations that additively increase A $\beta 42$ production, that is, three human APP mutations (Swedish mutations, K670N, M671L; Florida mutation, I716V; London mutation, V717I) and two mutant PSEN1 (M146L, L286V). Individually, each FAD mutation enhances A $\beta 42$ generation, but together they act synergistically to predominantly accumulate $\mathrm{A} \beta 42$. Thus, 5 XFAD mice already exhibit intraneuronal $\mathrm{A} \beta$ accumulation at 1.5 months, $\mathrm{A} \beta$ deposition at 2 months, and memory deficits at 4 months of age $[15,17-20]$. Furthermore, the 5XFAD model is one of a few known mouse models that exhibit significant neuronal loss in the hippocampus that correlates with accumulation of $\mathrm{A} \beta$ plaques $[15,21,22]$. However, in the cortex of 12 month-old 5XFAD mice, neuronal cell loss was reported to be predominately related to layer $5[15,23]$; the overall number of neurons in the frontal cortex and hippocampal CA1 region remained unchanged compared with age-matched wild-type (WT) mice [21]. Thus, cortical plasticity is likely to be impaired prior to hippocampal-dependent learning and memory deficits in 5XFAD mice [24]. It is noteworthy that 12-month-old 5XFAD mice were also reported to exhibit less anxiety, but normal locomotor behavior [21].

Intense efforts were carried out to characterize the transcription and expression profile in 5XFAD mice compared to WT. Using quantitative mass spectrometry to investigate proteome-wide changes in 4-month-old 5XFAD mice [24], alterations were predominantly identified in ApoE, ApoJ (clusterin), and nicastrin expression. NRF2 and p53 transcriptional pathways were activated, as well as IGF-1 signaling. Furthermore, various neurological glial marker proteins and factors implicated in neurological disorders such as AD, Parkinson's disease, Huntington's disease, and amyotrophic lateral sclerosis were affected [25]. Transcriptome analysis has also been carried out for the frontal cortex and cerebellum of 7-week-old 5XFAD mice [26].

Although neuropathological changes in $\mathrm{AD}$ have been well described previously, direct effects on systemic electrophysiological alterations have received less attention in the past. Currently, the impact of brain oscillation analysis as a novel tool in early diagnosis and prediction of disease progression is strongly discussed as functional impairments in $\mathrm{AD}$ can occur even without any significant neuronal loss and therefore could be independent of plaque formation [27-31]. Recent studies illustrated that altered hippocampal oscillatory activity correlates with an increase of $A \beta$ level and the appearance of plaques $[1,32,33]$, but slight changes in hippocampal and cortical network activity can also occur much earlier prior to clinical onset of $\mathrm{AD}[29-31,34,35]$. Alterations in network activities in $\mathrm{AD}$ are accompanied by an early imbalance of excitation and inhibition that elites overall changes in theta activity as a hallmark of hippocampal functioning $[1,20,36]$. These alterations due to $A \beta$ induced neuronal hyperexcitability [35] are accompanied by decreased GABAergic transmission within the hippocampus and can trigger seizure activity [37-44]. Neurons being early affected in $\mathrm{AD}$ pathogenesis are those of the septohippocampal circuitry, including cholinergic, GABAergic, and glutamatergic cells [45-53]. Interestingly, various mouse models of $\mathrm{AD}$ exhibit antithetic alterations in theta rhythmicity; that is, a number of them were reported to present cognitive decline associated with a paradoxical increase in theta activity $[27,54-57]$ whereas others displayed reduced theta rhythm [55]. The reason for either enhanced or impaired theta activity remains largely unknown. Though recent studies have gained substantial insight into the etiopathogenesis of $\mathrm{AD}$, we are still lacking detailed information about how septohippocampal dysfunction results in altered theta rhythmicity and neuronal hyperexcitability activity in AD.

In this study we combined seizure analysis, time-frequency-based theta analysis, and transcriptome data to elicit systemic cortical and hippocampal network alterations in the 5XFAD model of AD.

\section{Material and Methods}

2.1. Study Animals. This study was performed in $\mathrm{Tg}$ (APPSwFlLon, PSEN1 ${ }^{\star}$ M146L ${ }^{\star}$ L286V) 6799Vas (5XFAD) transgenic mice with a B6/SJL background overexpressing mutant forms of human APP (the Swedish mutations: K670N, M671L; the Florida mutation: I716V; the London mutation: V717I) and mutant PSEN1 (M146L, L286V). The 5XFAD mice were obtained from The Jackson Laboratory (JAX Mice Strains, USA) [15]. Five WT controls (body weight: $35.32 \pm 2.40 \mathrm{~g}$, age: $66.71 \pm 7.88$ weeks, 4 ô, 1 ᄋ) and five 5XFAD mice (body weight: $24.89 \pm 1.40 \mathrm{~g}$, age: $72.20 \pm 2.77$ weeks, all $\left.{ }^{*}\right)$ were analyzed in this study. All mice were housed in groups of 3-4 in clear Makrolon cages type II with ad libitum access to drinking water and standard food pellets. Using ventilated cabinets (Model 9AV125P, Tecniplast, Germany), mice were maintained at a temperature of $21 \pm 2^{\circ} \mathrm{C}, 50-60 \%$ relative humidity, and on a conventional $12 \mathrm{~h}$ light/dark cycle with the light cycle beginning at 5:00 a.m. for spontaneous epidural and deep, intracerebral EEG recordings.

All animal procedures were performed according to the Guidelines of the German Council on Animal Care and all protocols were approved by the Local Institutional and National Committee on Animal Care (Landesamt für Natur, Umwelt und Verbraucherschutz, LANUV, Germany). The authors further certify that all animal experimentation was carried out in accordance with the European Communities Council Directive of November 24, 1986 (86/609/EEC). Specific effort was made to minimize the number of animals used and their suffering.

\subsection{Stereotaxic EEG Electrode Implantation and Radiotele-} metric EEG Recordings. Mice were anesthetized using ketamine/xylazine $(100 / 10 \mathrm{mg} / \mathrm{kg}$ i.p.) and the radiotelemetry transmitter (TL11 M2-F20-EET 2-channel transmitter, Data Science International (DSI); specifications: weight $3.9 \mathrm{~g}$, volume $1.9 \mathrm{cc}$, input voltage range $\pm 1.25 \mathrm{mV}$, and channel bandwidth $1-50 \mathrm{~Hz}$ ) was implanted into a subcutaneous pouch on the back of the animals. The EEG electrodes of both transmitter channels were stereotaxically positioned using a computerized 3D stereotaxic StereoDrive (Neurostar, Germany). The differential epidural electrode of channel 1 targeting the primary motor cortex (M1) was positioned at the following coordinates referring to the bregma craniometric 
landmark: (+)-lead, cranial $+1 \mathrm{~mm}$, and lateral of bregma $1.5 \mathrm{~mm}$ (left hemisphere). For deep, intracerebral brain recordings targeting the hippocampal CA1 region the differential electrode of channel 2 was positioned as follows: $(+)-$ lead, caudal $-2 \mathrm{~mm}$, lateral of bregma $1.5 \mathrm{~mm}$ (right hemisphere), and dorsoventral (depth) $1.5 \mathrm{~mm}$. For both channels, epidural reference electrodes were placed on the cerebellar cortex at bregma $-6 \mathrm{~mm}$, lateral of bregma $1 \mathrm{~mm}$ (left hemisphere), and bregma $-6 \mathrm{~mm}$, lateral of bregma $1 \mathrm{~mm}$ (right hemisphere), respectively (see Supplementary Figure 1 of the Supplementary Material available online at http://dx.doi .org/10.1155/2015/781731). Electrodes were fixed using glass ionomer cement (Kent Express, UK) and the scalp was closed using Over and Over sutures (Ethilon, 6-0). To avoid hypothermia, supplemental warmth was given to the animal during the whole surgical procedure. A detailed description of the implantation procedure is given in [58]. For postoperative pain management animals were administered carprofen ( $5 \mathrm{mg} / \mathrm{kg}$ sc., Rimadyl, Parke-Davis/Pfizer, Germany). Animals were allowed to recover for 10 days prior to subsequent recordings. This recovery period is based on the observation that 10 days after surgery no difference in physiological parameters between transmitter implanted, nonimplanted, and sham-operated animals could be detected [59].

\subsection{Validation of EEG Electrode Placement. Seven controls} and six 5XFAD mice were originally implanted. To verify the correct electrode placement targeting the CA1 region, brains were extirpated postmortem and fixed in $4 \%$ paraformaldehyde. Afterwards, brains were cut to $60 \mu \mathrm{m}$ slices using a Vibroslice Tissue Cutter EMS 5000-MZ (Campden Instruments Limited) and hematoxylin-stained for visualization of the branch canal. Two controls and one 5XFAD mouse did not meet strict EEG electrode placement criteria and were thus excluded from the analysis.

2.4. EEG Data Acquisition. Ten days after radiotransmitter implantation, simultaneous video-EEG recordings from the motor cortex (M1) and the hippocampal CA1 region were performed for $48 \mathrm{~h}$ in all animals from both study groups using Dataquest ART 4.2 software (DSI) at a sampling rate of $500 \mathrm{~Hz}$ with no a priori filter cut-off.

\subsection{Electroencephalographic and Behavioral Seizure Analysis.} For further analysis data were exported to NeuroScore 2.1 (DSI). Qualitative and quantitative seizure analysis was performed using the NeuroScore seizure detection module. Spike parameters including dynamic and absolute threshold, spike duration, and spike intervals were adapted for different seizure protocols. Dynamic thresholds were based on multiplication of the root mean square (RMS) values of the EEG signals one minute prior to EEG segments being analyzed. The threshold ratio (minimum threshold) was defined as 2 while the maximum ratio was defined as 15. The minimum amplitude value of spikes was $100 \mu \mathrm{V}$ for the dynamic range. In case of the absolute threshold the maximum amplitude was fixed at $1000 \mu \mathrm{V}$ with a threshold value of $200 \mu \mathrm{V}$. In both seizure protocols the minimum spike duration was determined at $1 \mathrm{~ms}$ and the maximum spike and short/slow-wave duration at $100 \mathrm{~ms}$. Spike trains were detected with a minimum train duration of $0.5 \mathrm{~s}$ including at least 4 individual spikes. Spike intervals within a train were ranging between 0.05 and $0.3 \mathrm{~s}$. The interval between individual spike trains was determined at $1 \mathrm{~s}$. Seizure protocols contained the total number of seizure episodes and spikes, spike frequency, total spike train duration, shortest and longest spike train durations. Data were calculated and plotted throughout the figures as mean \pm standard error of the mean (SEM). Significance was calculated using Student's $t$-test which included pretesting for normal distributions via the Kolmogorov-Smirnov test.

2.6. Urethane Induced Theta Oscillations. Urethane (Sigma, Germany) was freshly dissolved in $0.9 \% \mathrm{NaCl}$ and systemically (i.p.) administered at $800 \mathrm{mg} / \mathrm{kg}$ to induce atropinesensitive type II theta oscillations. Four control mice from the original study group (body weight: $32.98 \pm 0.65 \mathrm{~g}$, age: $70.32 \pm 9.04$ weeks, $30^{\star}, 1$ o) and four 5XFAD animals from the original study group (body weight: $25.52 \pm 1.61 \mathrm{~g}$, age: $73.75 \pm 2.97$ weeks, all $\left.\delta^{t}\right)$ were used for this approach. CA1 recordings under baseline conditions (30 min duration) and under urethane (30 min duration 15 to 45 min after injection) were used for analysis of urethane induced hippocampal theta oscillations.

2.7. EEG Data Analysis. Complex EEG analysis was performed for spontaneous $48 \mathrm{~h}$ recordings at a sampling rate of $500 \mathrm{~Hz}$. Data segments with a length of $60 \mathrm{~min}$ each were extracted from the $48 \mathrm{~h}$ total recordings. Data segments were analyzed using complex Morlet wavelets to calculate both frequency and amplitude of oscillations. The complex Morlet wavelet is defined as

$$
\Psi(x)=(\pi b)^{(-1 / 2)} \exp (2 \pi i c x) \exp \left(-\frac{x^{2}}{b}\right),
$$

where $b$ is the bandwidth parameter, $c$ the center frequency, and $i$ the imaginary unit [60]. This wavelet or similar ones have often been applied in the literature to study EEG data, as they guarantee optimal resolution in both frequency and time $[60,61]$. In our case, the bandwidth parameter and center frequency were both set to 3 in order to weight the frequency resolution to distinguish frequency differences on the $0.1 \mathrm{~Hz}$ level, but not to neglect a sufficient time resolution. EEG data were analyzed in the frequency range of $0.2-12 \mathrm{~Hz}$ with a step size of $0.1 \mathrm{~Hz}$, thus including the typical delta, theta, and alpha frequency ranges. In order to apply the wavelet technique for extraction of theta-oscillatory segments, we developed a taskadjusted detection criterion. This theta detection method mimicked the standard visual inspection of theta oscillations and was substantially based on a complex elaboration of the frequency architecture of theta activity [62].

Theta-positive oscillatory segments of $2.5 \mathrm{~s}$ duration were defined as follows ( $A_{\max }$ : maximum amplitude):

$$
\frac{A_{\max (4-12 \mathrm{~Hz})}(\mathrm{mV})}{A_{\max (2-3.9 \mathrm{~Hz})}(\mathrm{mV})}>2 .
$$


TABLE 1: Sequence of primer pairs used for qPCR.

\begin{tabular}{lcccc}
\hline Gene & \multicolumn{1}{c}{ Forward sequence } & Reverse sequence & Accession number & Size (bp) \\
\hline HPRT $^{1}$ & GCTGGTGAAAAGGACCTCT & CACAGGACTAGAACACCTGC & J00423 & 249 \\
Kcnmal $^{2}$ & CCTGAAGGACTTTCTGCACAAGG & ACTCCACCTGAGTGAAATGCCG & NM_010610 & 122 \\
Cacna2d1 $^{2}$ & GTGGAAGTGTGAGCGGATTGAC & TCGCTTGAACCAGGTGCTGGAA & NM_001110843 & 150 \\
Prkcb $^{2}$ & CCAAGATGACGATGTGGAGTGC & CTCCATCACAAAGTACAGGCGG & NM_008855 & 127 \\
Cacnale $^{1,3}$ & GGAGGTCAGCCCGATGTC & GGGCTCCTCTGGTTGTCC & L29346 & 420,399, and 363 \\
Plcd ${ }^{2}$ & TCTCGCGCAATATGCCTTCCAG & ATCTCGGTCAGATGGTGTGCCA & NM_148937 \\
Scn8a & CCCGGCAGGAGCCGA & CACTGTTTGGCTTGGGCTTG & NM_001077499.2 & 108 \\
Plcb1 & AGCCAGATGGAAGAGGAGAAG & TCATGGCAACCTTCCGACAA & NM_019677.2 \\
Casp8 & ATGGCTACGGTGAAGAACTGCG & TAGTTCACGCCAGTCAGGATGC & NM_009812 & 235 \\
\hline
\end{tabular}

${ }^{1}$ Weiergräber et al. (2005) [58]; Basic Res Cardiol.

${ }^{2}$ Commercially available at http://www.origene.com/.

${ }^{3}$ II-III-loop.

The $2.5 \mathrm{~s}$ time length is suited to precisely analyze theta activity [20]. Some extracted theta segments did not correspond to normal theta activity and were related to spontaneous behavior, for example, eating or scratching as proven by video analysis of the mice. To eliminate these segments, a specific algorithm was developed and validated. All theta segments with a mean frequency lower than $5 \mathrm{~Hz}$ or higher than $10 \mathrm{~Hz}$, exhibiting only slight frequency changes over time, were excluded from the analysis. Finally, sorted EEG segments identified as theta oscillation epochs were statistically analyzed and all data were displayed as mean \pm SEM. Furthermore, activity data of mice during $48 \mathrm{~h}$ recordings and the conventional $12 \mathrm{~h} \mathrm{light/dark} \mathrm{cycle} \mathrm{(beginning} \mathrm{at} \mathrm{5:00} \mathrm{a.m.)}$ were used to correlate theta activity from the CAl region with either the active or nonactive state. All EEG calculations were done using custom-made programs in MATLAB (The MathWorks Inc., Version R2012b).

2.8. Gene Expression Profiling Using Microarray Procedure. Total RNA (250 ng) was prepared from the hippocampi of three independent control mice (age: $68.10 \pm 0.05$ weeks, $2{ }^{*}$, 1 ) and three independent 5XFAD animals (age: 68.24 \pm 0.75 weeks, $2 \lesssim, 1$ ᄋ) that were not involved in any other experimental procedures before using RNeasy Lipid Tissue Mini Kit (Qiagen). Microarray experiments were carried out using Mouse Exon ST arrays (Affymetrix). Arrays were washed and stained according to the manufacturer's recommendations. Labeled and purified cDNA was fragmented $(5.5 \mu \mathrm{g})$ and subsequently hybridized to the arrays before scanning in a GeneChip 3000 7G scanner (Affymetrix). Normalization to the median of all samples, background correction, and statistical analysis were performed with GeneSpringGX software (Agilent technologies). An implemented GC-RMA algorithm was applied on all chips to summarize probe level information. Microarray data were analyzed using unpaired $t$-tests. An uncorrected significance level $P<0.05$ was adopted in all instances. Differentially regulated transcripts with a fold change (FC) greater than 1.6 were then subject to hierarchical clustering analysis in order to visualize gene expression changes across groups. Array data are available in the GEO database under GSE50521. DAVID [63, 64] was used to carry out gene ontology enrichment analyses in the gene set differentially expressed between 5XFAD and WT controls.
2.9. RNA Extraction and Quantitative Real-Time PCR ( $q P C R$ ). Quantitative real-time PCR was used to validate potential gene candidates that exhibited transcriptional alterations in microarray analysis. The cDNA synthesis from hippocampal RNA (see above) was carried out using anchored-oligo(dt)18 and hexamer primer in a two-step RT-PCR approach (Transcriptor First Strand cDNA Synthesis Kit, Qiagen) and qPCR reaction protocol was based on LightCycler 480 SYBR Green I Master (Roche). The qPCR was performed in a Light Cycler 480 System (Roche) thermocycler. The following cycler protocol was used for all primer pairs (Table 1): $95^{\circ} \mathrm{C}(10 \mathrm{~min}$, preincubation step); $95^{\circ} \mathrm{C}\left(10 \mathrm{~s}\right.$, melting step); $60^{\circ} \mathrm{C}(20 \mathrm{~s}$, annealing step); and $72^{\circ} \mathrm{C}(30 \mathrm{~s}$, extension step), 35 cycles. The specificity of the amplification was checked by melting curve analysis and the products were identified by electrophoresis. Deionized, nuclease-free water (no cDNA) and total RNA samples (without RT) were used as controls and HPRT was used as an internal reference gene. The $\mathrm{Ct}$ (cycle threshold) values were calculated using the LightCycler 480 System software. Fold changes (FC) of Cacna2d1, Kcnmal, Cacnale, Prkcb, Plcd4, Scn8a, Plcb1, and Casp8 gene expression in 5XFAD transgenic mice related to WT controls were calculated according to [65].

2.10. Statistical Analysis. Further statistical analyses concerning duration, frequency, amplitude of theta segments, and comparisons between groups and experimental conditions were done with IBM SPSS Statistics, Version 22 (IBM Corporation, 2013). The Kolmogorov-Smirnov test was used to test for normal distributions. Student's $t$-test was used to detect differences between the two groups of the abovementioned parameters. For data that did not show a normal distribution, the Mann-Whitney $U$ test was used instead, where we made use of the exact solution. This is necessary since the asymptotic solution overestimates the $P$ value for small numbers of animals per group. For analysis of urethane induced theta oscillations the repeated measures ANOVA with within-subjects factor, that is, experimental condition (baseline versus after urethane) and between-subjects factor, that is, genotype (control mice versus 5XFAD mice) was applied. The Simes-Hochberg "step-up" procedure was used to correct for multiple testing, if necessary [66]. This procedure was utilized at a $P$-level of 0.05 . 


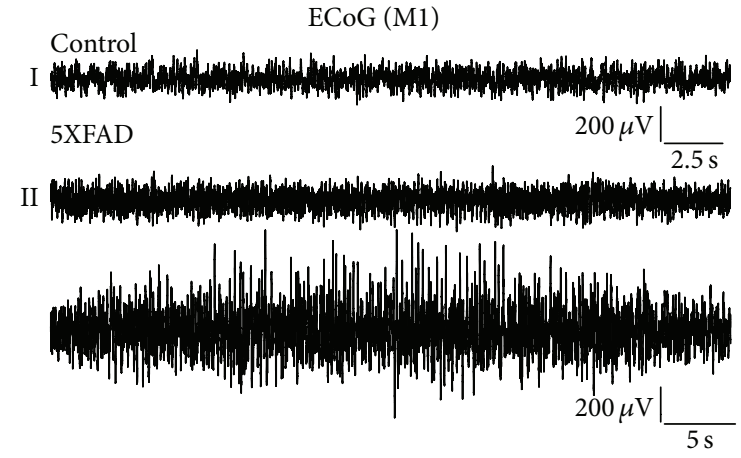

(a)

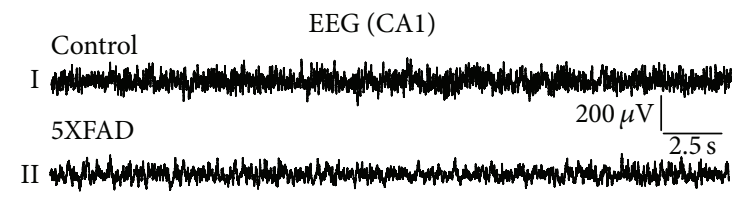

(b)

FIGURE 1: Electroencephalographic (EEG) characteristics of controls and 5XFAD mice. EEGs recorded from the primary motor cortex (M1) as electrocorticogram (ECoG) (a) and the hippocampal CA1 region as electrohippocampogram (b) from both WT and 5XFAD mice. In the CA1 electrohippocampogram neither controls (b)I nor 5XFAD mice (b)II exhibited typical ictal discharges in $48 \mathrm{~h}$ longterm recordings. Electrocorticographic M1 recordings, however, exhibited subclinical, that is, electroencephalographic seizure activity in 5XFAD mice of different severity (a)II that was not detectable in control mice (a)I. (a)I, (b)I, and b(II): 30 sec duration; (a)II $50 \mathrm{sec}$ duration.

\section{Results}

3.1. Phenotypical Characterization. As reported previously, 5XFAD mice exhibited a reduced body weight in comparison to their WT littermates $(24.89 \pm 1.40 \mathrm{~g}, n=5 \mathrm{v} .35 .32 \pm 2.40 \mathrm{~g}$, $n=5$, df $=8, t=3.757$, and $P=0.006)$. The same holds true for a characteristic clasping phenotype involving a simultaneous retraction of both fore- and hindpaws [21].

\subsection{Electrocorticographic Characteristics of Control and} 5XFAD Mice. In this study epidural M1 and deep intrahippocampal CA1 long-term $(48 \mathrm{~h})$ EEG recordings were obtained in 5XFAD $(n=5)$ and WT $(n=5)$ mice (Figure 1$)$. EEG recordings were combined with simultaneous videorecordings to detect potential movement artefacts and to differentiate convulsive from nonconvulsive seizure activity. 5XFAD mice exhibited aberrant hyperexcitability in the M1 recording depicting typical episodes or trains of spike, polyspike, and spike-wave activity (Figure 1(a)II) whereas WT mice did not (Figures 1(a)I and 1(b)I). Video analysis revealed that none of the motor cortex seizures were associated with motoric exacerbation, thus remaining subclinical or nonconvulsive.

3.3. Seizure Analysis in Control and 5XFAD Mice. The seizure phenotype of 5XFAD mice $(n=5)$ and WT mice $(n=$ 5) was analyzed using simultaneous video-EEG recordings for a total duration of $48 \mathrm{~h}$ (Figure 2). None of the WT littermates exhibited aberrant hyperexcitability according to the automated seizure scoring system (NeuroScore 2.1, DSI). In contrast, 5XFAD mice displayed ictal-like discharges, such as spikes, polyspikes, and spike-waves. These discharges were capable of forming seizure episodes characterized by seizure initiation, seizure prolongation, and seizure termination. Interictal discharges originated from single spike activity in most cases. None of this aberrant hyperexcitability was accompanied by apparent motoric exacerbation, for example, forelimb clonus, rearing and falling, or generalized tonicclonic seizures. However, minor motor activity including, for example, orofacial clonus or partial isolated clonus or tonus of the limbs, can be very subtle and thus cannot be fully excluded. In summary, the total number of seizure episodes was $13.00 \pm 11.05$, the total number of spikes: $51.40 \pm 43.37$, the spike frequency: $5.26 \pm 1.32 \mathrm{~Hz}$, and the total spike train duration: $8.84 \pm 7.55 \mathrm{sec}$ (Figures 2(a)-2(d)). Further seizure parameters in 5XFAD mice included the spike train duration of $0.51 \pm 0.13 \mathrm{sec}$, the number of spikes per train of $3.22 \pm 0.81$, the maximum spike train duration of $0.64 \pm 0.19 \mathrm{sec}$, and the minimum spike train duration $0.46 \pm 0.12 \mathrm{sec}$ (Figures $2(\mathrm{e})-2(\mathrm{~h})$ ). These seizures turned out to be subclinic or nonconvulsive and were prominent in the M1 deflection. However, a single 5XFAD mouse exhibited convulsive tonic-clonic seizures of status-like character with prominent interictal spike activity (not shown) and died during the early recovery period. Thus, it was excluded from further analysis. Interestingly, 5XFAD mice did not show ictal discharges in the deep, intrahippocampal CA1 recording (Figure 1(b)I). Disinhibitory tendencies as being shown in our seizure analysis were speculated to be relevant also for reduced anxiety in 5XFAD mice [21].

3.4. Differential Gene Expression Detected by Microarray Anal$y$ sis. Alzheimer's disease is associated with considerable transcriptional alterations in key brain areas. Gene expression analysis employing Mouse Exon ST arrays (Affymetrix) on hippocampal tissue revealed 1421 transcripts differentially regulated between 5XFAD mice and WT controls. The statistical analysis applied an uncorrected significance level of $P<0.05$. Array data and further detailed information are available in the GEO database under GSE50521. Candidates which are likely to be of interest for seizure and theta activity are depicted in Supplementary Table 1. Those with FC > 2 are listed in Supplementary Table 2. Gene ontology analysis revealed that the strongest transcriptional alterations belong to immune-response and inflammation related genes observed in the context of late-stage cerebral amyloidosis.

3.5. Changes in Gene Expression Levels in 5XFAD Mice Compared with WT Controls. We performed qRT-PCR on hippocampi from three independent WT controls and three independent 5XFAD mice to determine gene expression changes. Among the differentially expressed genes in the microarray assay, we chose eight genes for qRT-PCR analysis based on their involvement in the theta-genesis pathway. The selected genes and their qPCR primers are listed in Table 1. Among the eight genes tested, qPCR revealed upregulation 


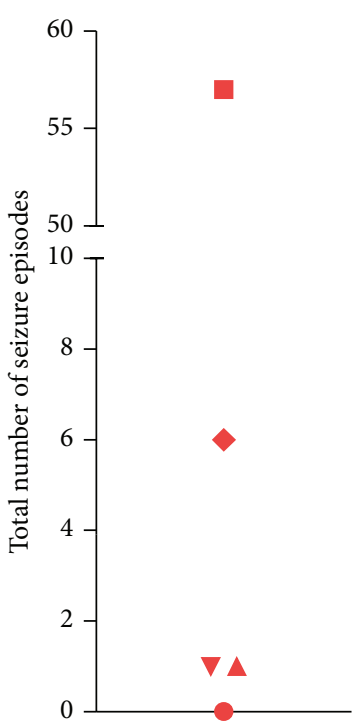

(a)

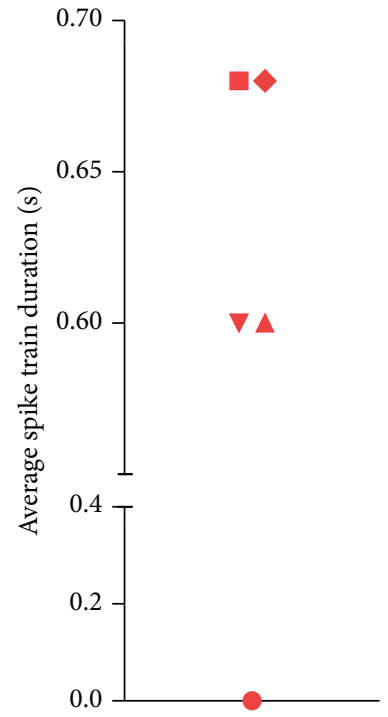

(e)

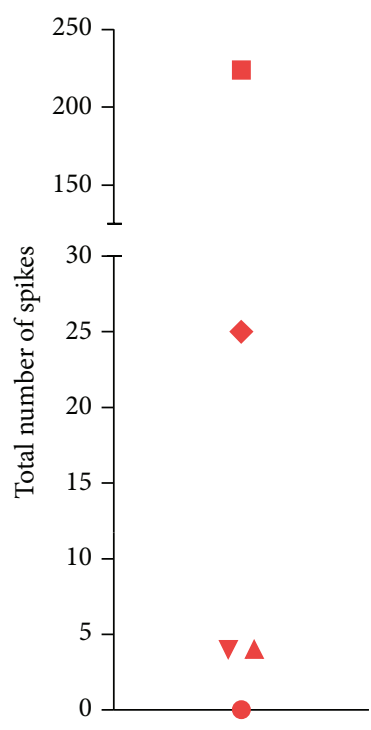

(b)

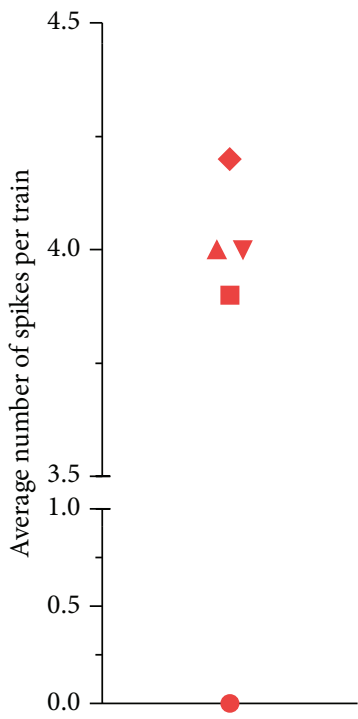

(f)

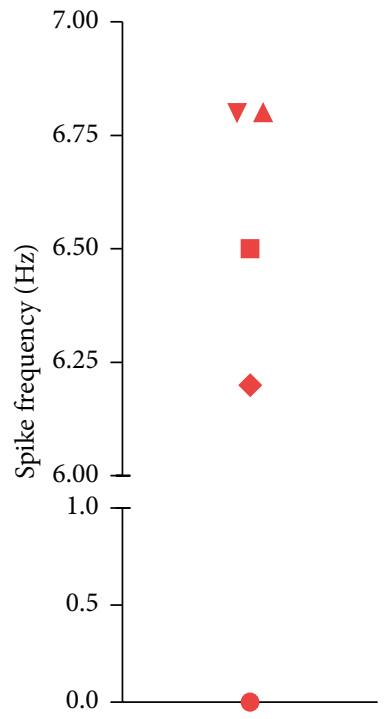

(c)

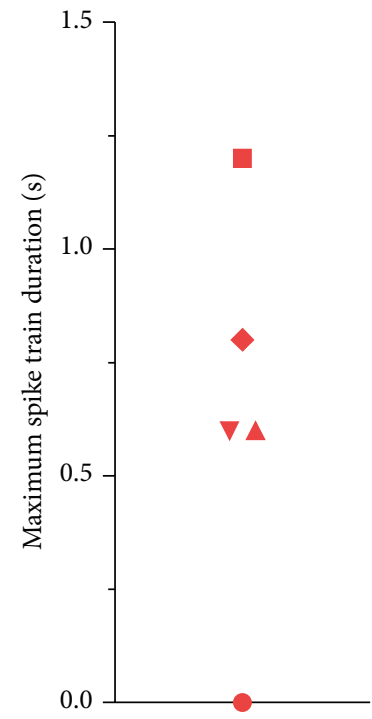

(g)

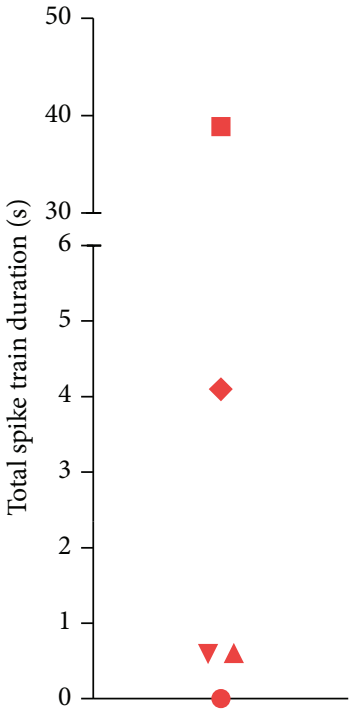

(d)

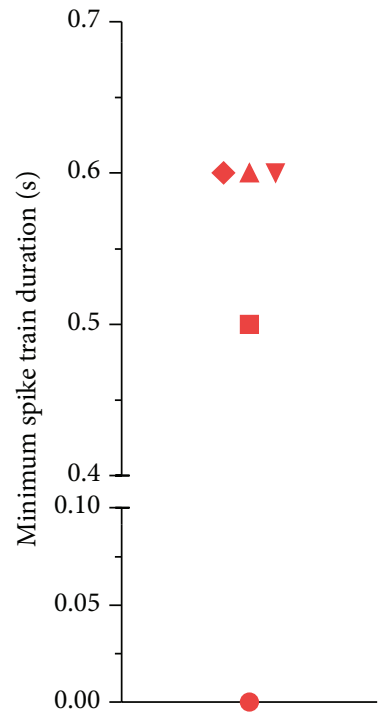

(h)

FIGURE 2: Seizure characteristics in control and 5XFAD mice. Dot plots illustrating results for individual 5XFAD mice. Total number of seizure episodes (a) and spikes (b), spike frequency (c), total (d) and average (e) spike train duration, average number of spikes per train (f), and maximum (g) and minimum spike train duration (h) are depicted. Parameters were analyzed using the NeuroScore Automated Seizure Module (DSI). Note that 5XFAD mice exhibited ictal discharges of highly variable degree whereas none of the controls displayed ictal-like discharges (not shown).

of Casp8 (FC: 2.0979, Table 2) which is likely to be responsible for neuronal cell loss in 5XFAD mice based on altered regulating of microglia activation through a PKC- $\delta$ dependent pathway [67]. The Scn8a Na ${ }^{+}$channels as well as Kcnmal $\mathrm{K}^{+}$ channels were not changed in transcription. Interestingly, microarray analysis suggested potential alterations in the muscarinic signal transduction pathway including Plcbl, Plcd4, Prkcb, Cacnale, and Cacna2d1 that might be relevant for theta oscillations [62]. Validation of these components finally supported an increase in Plcd4 transcript levels (FC: 1.6105) whereas no substantial fold change could be detected for the other factors (Figure 3, Table 2).
3.6. Intrinsic Hippocampal Oscillatory Activity in WT Control and 5XFAD Mice. Prior to analysis of the hippocampal oscillatory behavior, we analyzed motor activity in control and 5XFAD mice as active exploratory behavior is associated with a different type of theta entity as compared to, for example, alert immobility (Figure 4). Movement in the horizontal plane was automatically determined by the recording system. The total time of motor activity did not change between controls and 5XFAD mice $(9.10 \pm 0.72 \mathrm{~min} / \mathrm{h}$ versus $9.59 \pm 1.77 \mathrm{~min} / \mathrm{h}$, Figure 5(a)). The same holds true for motor activity during the light phase $(8.11 \pm 1.23 \mathrm{~min} / \mathrm{h}$ versus $8.72 \pm 1.36 \mathrm{~min} / \mathrm{h}$, Figure $5(\mathrm{~b}))$ and dark phase 
Plcb1

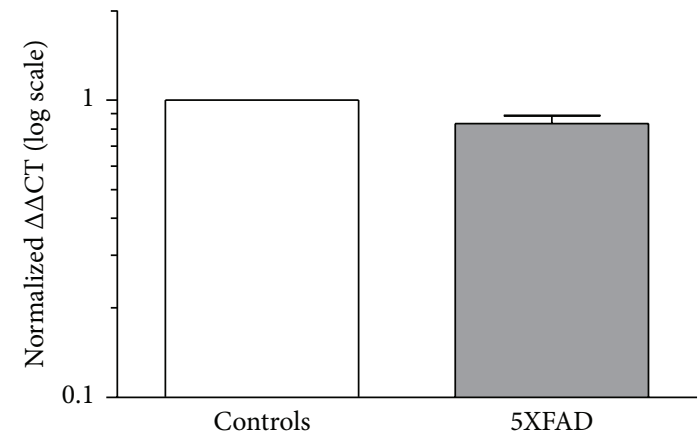

(a)

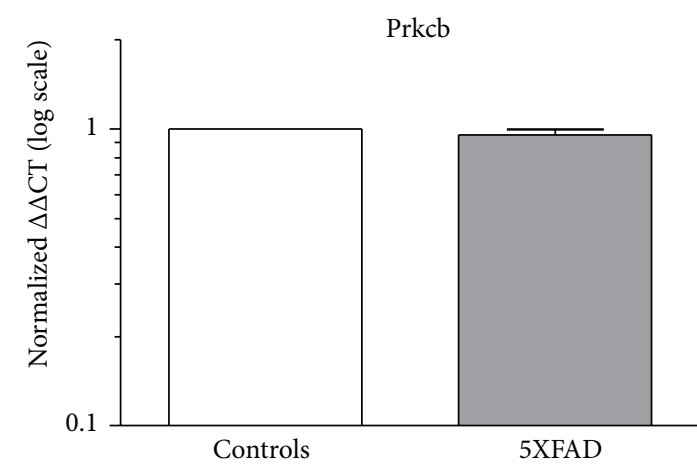

(c)

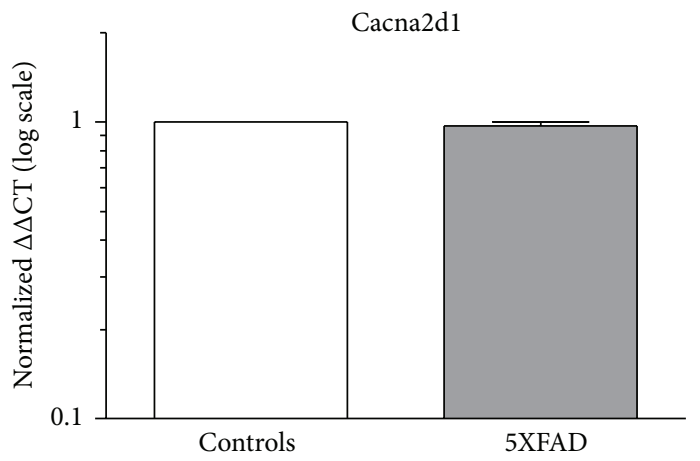

(e)

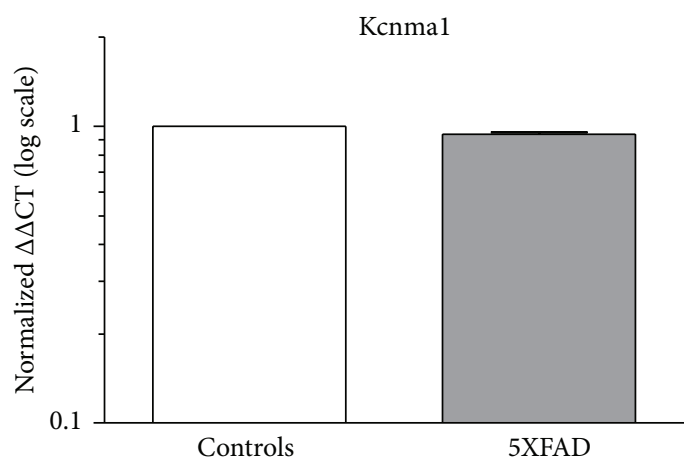

(g)
Plcd4

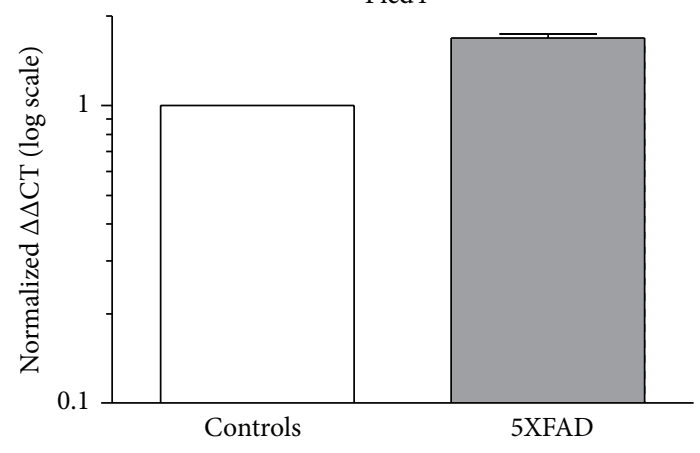

(b)

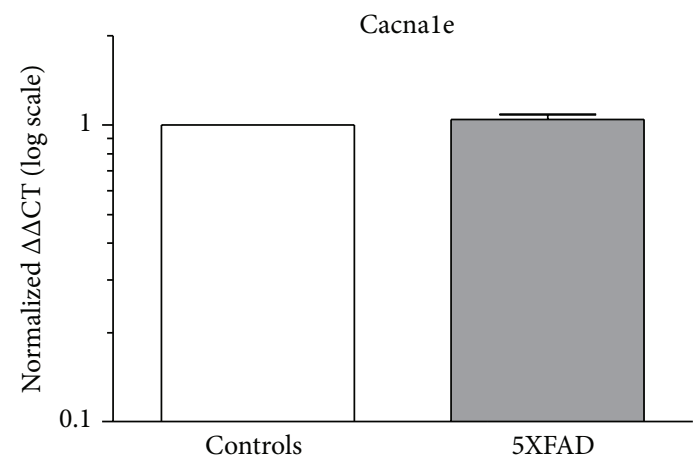

(d)

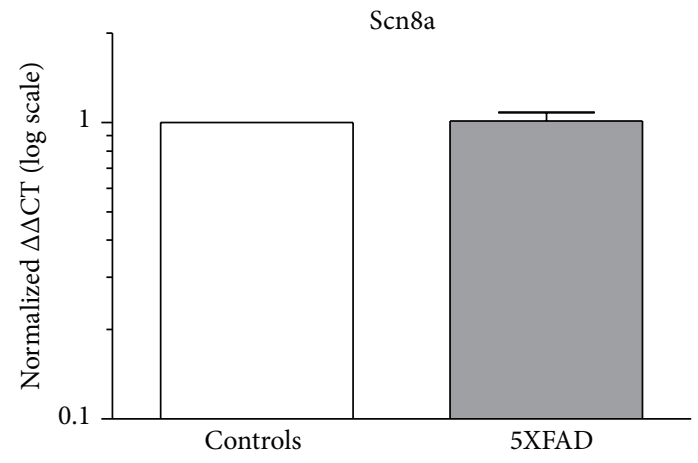

(f)

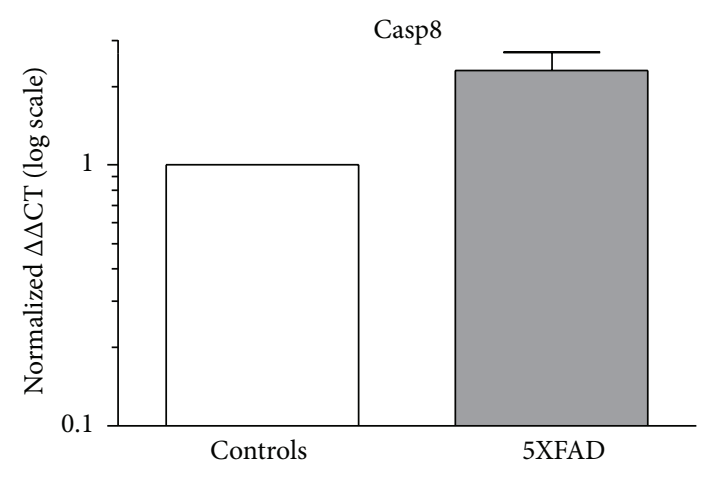

(h)

FIGURE 3: Gene transcription profiles in 5XFAD mice. RNA extracted from the hippocampus of control and 5XFAD mice was used for microarray analysis. A selected number of candidates which exhibited altered expression profile in microarray analysis were further validated using quantitative real-time PCR (qPCR). Normalized $\Delta \Delta$ CT (log scale) for Cacna2d1, Kcnmal, $\mathrm{Ca}_{\mathrm{v}} 2.3_{\text {II-III }}$-loop, Prkcb, Plcb1, Scn8a, Plcd4, and Casp8 is depicted. Note that a minor decrease in Plcb1 transcript levels turned out to exist, but a clear increase in Plcd4 in 5XFAD mice. 


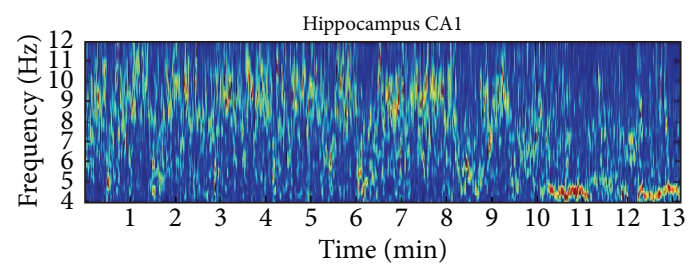

(a)

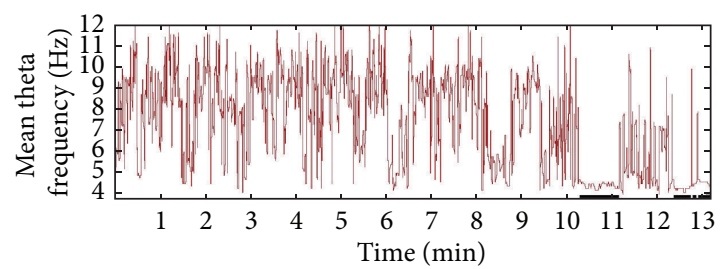

(b)

FIGURE 4: Time-frequency analysis of theta activity in control and 5XFAD mice. (a) Color-coded time-frequency plot of extracted theta segments from EEG data. These segments were clued together (13 minutes in total) for a better demonstration of the oscillatory activity. The $y$-axis represents the frequency range of $4-12 \mathrm{~Hz}$. (b) Mean theta frequency $(\mathrm{Hz})$ calculated for the hippocampal thetaalpha band (4-12 Hz). Note that (a) and (b) display specific episodes of consistent, high amplitude, low frequency EEG activity that was proven to be related to behavioral aspects such as grooming, scratching, or eating based on video analysis. A specific algorithm was defined to automatically detect and eliminate these episodes from further evaluation (black bars, (b)).

TABLE 2: Fold changes in gene expression of 5XFAD transgenic mice compared to WT controls.

\begin{tabular}{lc}
\hline Gene & Fold change \\
\hline Kcnmal & $-1,0643$ \\
Cacna2d1 & $-1,0331$ \\
Prkcb & $-1,0546$ \\
Cacnale & 1,0437 \\
Plcd4 & 1,6105 \\
Scn8a & $-1,0344$ \\
Plcb1 & $-1,1765$ \\
Casp8 & 2,0979 \\
\hline
\end{tabular}

$(10.09 \pm 1.05 \mathrm{~min} / \mathrm{h}$ versus $10.46 \pm 2.52 \mathrm{~min} / \mathrm{h}$, Figure $5(\mathrm{c}))$. These results correlate with findings from [21] for exploratory and spontaneous locomotor activity in 5XFAD mice aged 9 to 12 months.

As expected, however, there was an increase in motor activity from light to dark phase in both genotypes (Figures 5(b) and 5(c)). Based on these findings, alterations in 5XFAD theta architecture cannot be attributed to changes in activity pattern.

To determine whether hippocampal theta oscillations were indeed altered in 5XFAD mice, we performed spontaneous $48 \mathrm{~h}$ video-EEG recordings from the CA1 region of the hippocampus from both controls and 5XFAD mice. Using a time-frequency approach, theta duration, theta frequency, and theta amplitude were calculated. First, theta duration was analyzed for both motor and nonmotor activity. No significant changes were observed for controls compared to 5XFAD mice during the total observation period $(5.44 \pm 2.24 \mathrm{~min} / \mathrm{h}$ versus $7.36 \pm 0.89 \mathrm{~min} / \mathrm{h}$, Figure $6(\mathrm{a}))$, the light phase $(5.29 \pm$ $2.21 \mathrm{~min} / \mathrm{h}$ versus $6.03 \pm 1.06 \mathrm{~min} / \mathrm{h}$, Figure $6(\mathrm{~b}))$, or the dark phase $(5.59 \pm 2.27 \mathrm{~min} / \mathrm{h}$ versus $8.69 \pm 1.16 \mathrm{~min} / \mathrm{h}$, Figure 6(c)). However, data suggested that there might be an increase in theta during the dark phase (Figure 6(c)). During nonmotor activity again no significant differences were detected for the total duration $(3.89 \pm 1.53 \mathrm{~min} / \mathrm{h}$ versus $4.87 \pm 0.57 \mathrm{~min} / \mathrm{h}$, Figure $6(\mathrm{~d}))$, the light phase $(3.91 \pm$ $1.50 \mathrm{~min} / \mathrm{h}$ versus $4.03 \pm 0.59 \mathrm{~min} / \mathrm{h}$, Figure $6(\mathrm{e}))$, or the dark phase $(3.86 \pm 1.56 \mathrm{~min} / \mathrm{h}$ versus $5.71 \pm 0.70 \mathrm{~min} / \mathrm{h}$, Figure 6(f)). During the dark phase of no motor activity a tendency of increased theta duration was observed again, particularly in relation to the light phase. Based on this observation we analyzed the percentage change of theta from light phase (LP) to dark phase (DP) via (LP/DP - 1) * 100 . For the total $48 \mathrm{~h}$ observation period, a significant trend was observed between controls and 5XFAD mice $(-5.55 \pm$ 5.77 versus $-28.77 \pm 10.56, \mathrm{df}=8, t=1.928, P=$ 0.090 , Figure $7(\mathrm{a}))$; for nonmotor activity this change turned out to be significant $(5.11 \pm 4.88$ versus $-27.51 \pm 8.99, \mathrm{df}=$ $8, t=3.189, P=0.013$, Figure $7(\mathrm{~b}))$. Theta analysis during motor activity did not reveal any statistical differences (light and dark: $1.56 \pm 0.72 \mathrm{~min} / \mathrm{h}$ versus $2.49 \pm 0.48 \mathrm{~min} / \mathrm{h}$; light: $1.38 \pm 0.72 \mathrm{~min} / \mathrm{h}$ versus $2.00 \pm 0.50 \mathrm{~min} / \mathrm{h}$; dark: $1.73 \pm$ $0.76 \mathrm{~min} / \mathrm{h}$ versus $2.98 \pm 0.74 \mathrm{~min} / \mathrm{h}$ ).

An important parameter to be affected during the pathogenesis of Alzheimer's disease in humans is theta frequency [68-71]. For the total recording period (light and dark phase) and the dark phase there was a tendency of reduced theta frequency in 5XFAD mice $(7.04 \pm 0.28 \mathrm{~Hz}$ versus $6.50 \pm$ $0.20 \mathrm{~Hz}$, Figure 8(a); $6.77 \pm 0.25 \mathrm{~Hz}$ versus $6.29 \pm 0.23 \mathrm{~Hz}$, Figure $8(\mathrm{c})$ ) with a statistical trend during the light phase $(7.09 \pm 0.26 \mathrm{~Hz}$ versus $6.48 \pm 0.19 \mathrm{~Hz}, \mathrm{df}=8, t=1.896, P=$ 0.095 , Figure $8(\mathrm{~b}))$. For the nonmotor activity, the same phenomenon was observed with no significant change during the dark phase $(6.77 \pm 0.25 \mathrm{~Hz}$ versus $6.29 \pm 0.23 \mathrm{~Hz}$, Figure $8(f))$, a significant trend for the total observation period $(6.92 \pm$ $0.22 \mathrm{~Hz}$ versus $6.32 \pm 0.21 \mathrm{~Hz}, \mathrm{df}=8, t=1.989, P=0.082$, Figure $8(d))$ and a significant reduction during the light phase $(7.06 \pm 0.22 \mathrm{~Hz}$ versus $6.35 \pm 0.21 \mathrm{~Hz}, P=0.045$, Figure $8(\mathrm{e}))$. No significant differences in theta frequency were observed for motor activities (light and dark: $7.17 \pm 0.38 \mathrm{~Hz}$ versus $6.69 \pm 0.18 \mathrm{~Hz}$; light: $7.12 \pm 0.33 \mathrm{~Hz}$ versus $6.61 \pm 0.18 \mathrm{~Hz}$; dark: $7.23 \pm 0.42 \mathrm{~Hz}$ versus $6.76 \pm 0.23 \mathrm{~Hz}$ ).

Finally, the mean theta amplitudes were calculated. For the total recording period, no changes in theta amplitude could be detected (light and dark: $0.019 \pm 0.004 \mathrm{mV}$ versus $0.018 \pm 0.003 \mathrm{mV}$, light: $0.019 \pm 0.004 \mathrm{mV}$ versus $0.018 \pm$ $0.003 \mathrm{mV}$; and dark: $0.019 \pm 0.004 \mathrm{mV}$ versus $0.018 \pm 0.003 \mathrm{mV}$, Supplementary Figure $2(\mathrm{~A}-\mathrm{C})$ ). The same holds true for the nonmotor activity (light and dark: $0.020 \pm 0.004 \mathrm{mV}$ versus $0.018 \pm 0.003 \mathrm{mV}$; light: $0.020 \pm 0.004 \mathrm{mV}$ versus $0.018 \pm$ $0.003 \mathrm{mV}$, and dark: $0.019 \pm 0.004 \mathrm{mV}$ versus $0.018 \pm 0.003 \mathrm{mV}$, Supplementary Figure 2(D-F)) and nonmotor phase. This finding correlates with previous observations in 5XFAD but also TgCRND8 mice [20]. 


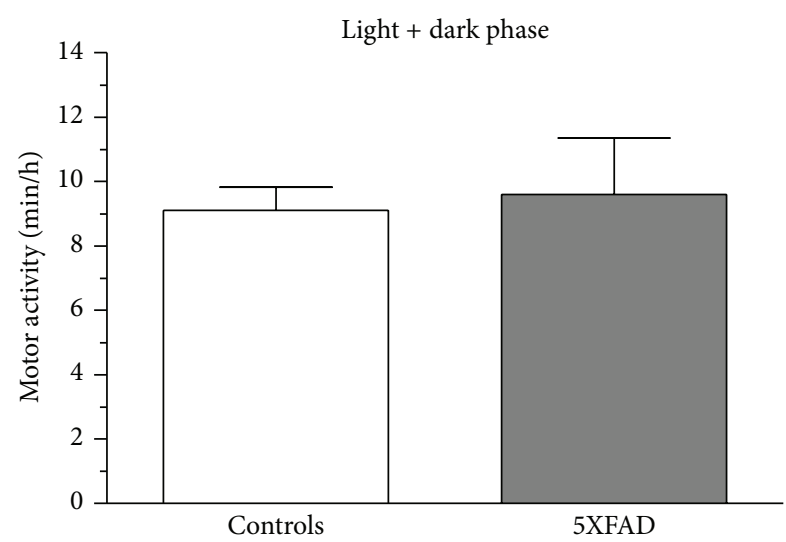

(a)

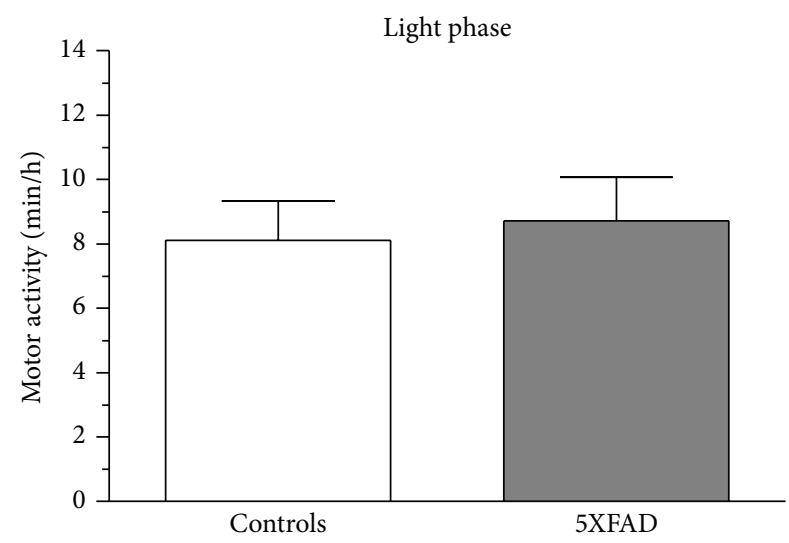

(b)

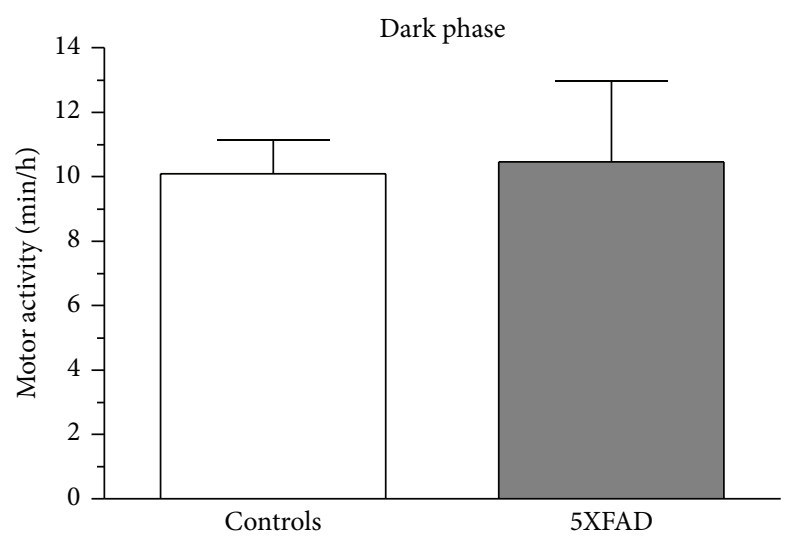

(c)

FIGURE 5: Motor activity in controls and 5XFAD mice. The radiotelemetry system is capable of measuring movement in the horizontal plane as relative units. $10 \mathrm{~s}$ epochs were categorized in a binary fashion as motor segments or nonmotor segments. Motor activity was then calculated as $(\mathrm{min} / \mathrm{h})$ for the whole observation period (light + dark phase, (a)) and the light (b) and dark phases (c) separately. No difference was observed between both genotypes.

3.7. Urethane Induced Hippocampal Theta Oscillations in Controls and 5XFAD Mice. Besides analysis of spontaneous theta activity, we also investigated urethane induced theta oscillations in 5XFAD $(n=4)$ and WT mice $(n=4)$. Pharmacodynamically, urethane has a multitarget character capable of inducing atropine-sensitive type II theta. Theta oscillations were analyzed for $30 \mathrm{~min}$ baseline and $30 \mathrm{~min}$ postinjection episodes (Figure 9). The duration of hippocampal theta oscillations for the total analytical period, that is, including theta oscillations during episodes with either motor or nonmotor activity, was increased in control mice $(1.59 \pm 0.47 \mathrm{~min} / \mathrm{h}$ to $4.20 \pm 1.40 \mathrm{~min} / \mathrm{h}, n=4)$ as in $5 \mathrm{XFAD}$ mice $(5.09 \pm 2.06 \mathrm{~min} / \mathrm{h}$ to $18.08 \pm 6.25 \mathrm{~min} / \mathrm{h}, n=4)$ and the factor "experimental condition/urethane effect" exhibited significance $(F(1,6)=$ 7.270, $P=0.036)$. The "genotype" factor exhibited a statistical trend $(F(1,6)=5.256, P=0.062$, Figure 9(a)). As type II theta is characteristic of alert immobility data were also analyzed for nonmotor activity EEG segments. As expected, the results matched those for the total analytical period, that is, a significant effect for the factor "experimental condition/urethane effect" $(F(1,6)=7.691, P=0.032)$ with increase in controls $(1.45 \pm 0.48 \mathrm{~min} / \mathrm{h}$ to $3.88 \pm 1.52 \mathrm{~min} / \mathrm{h}$, $n=4)$ and 5 XFAD mice $(4.11 \pm 1.59 \mathrm{~min} / \mathrm{h}$ to $15.78 \pm$ $5.34 \mathrm{~min} / \mathrm{h}, n=4)$. The factor "genotype" exhibited a statistical trend $(F(1,6)=5.148, P=0.064$, Figure $9(\mathrm{~b}))$. These findings demonstrate that 5XFAD mice even of higher age are capable of displaying increased theta oscillations upon urethane provocation. However, it remains to be determined whether such theta activity is physiologically integrated or the result of hyperactive, functionally dislinked neuronal clusters within the hippocampus. Interestingly, besides an effect on theta duration, there was a significant effect for the factor "experimental condition/urethane effect" $(F(1,6)=13.536$, $P=0.010)$ on theta oscillation frequency for the total analytical period $(6.57 \pm 0.61 \mathrm{~Hz}$ to $5.48 \pm 0.36 \mathrm{~Hz}(n=4)$ in controls versus $6.18 \pm 0.31 \mathrm{~Hz}$ to $5.11 \pm 0.33 \mathrm{~Hz}(n=4)$ in $5 \mathrm{XFAD}$ mice, Figure $9(\mathrm{c}))$. This significant effect $(F(1,6)=8.036$, $P=0.030)$ also holds true for the nonmotor episodes $(6.60 \pm$ $0.63 \mathrm{~Hz}$ to $5.44 \pm 0.35 \mathrm{~Hz}(n=4)$ in controls versus $6.14 \pm$ $0.53 \mathrm{~Hz}$ to $5.15 \pm 0.36(n=4)$ in 5XFAD mice (Figure $9(\mathrm{~d})$ ). 


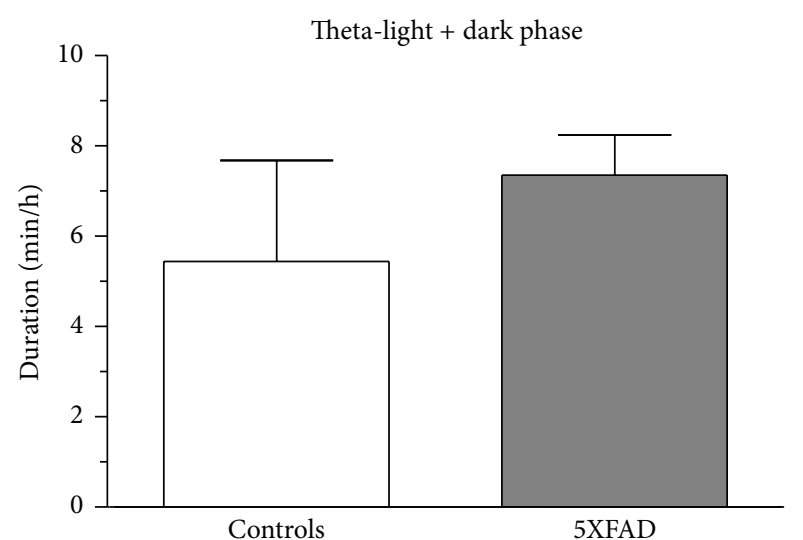

(a)

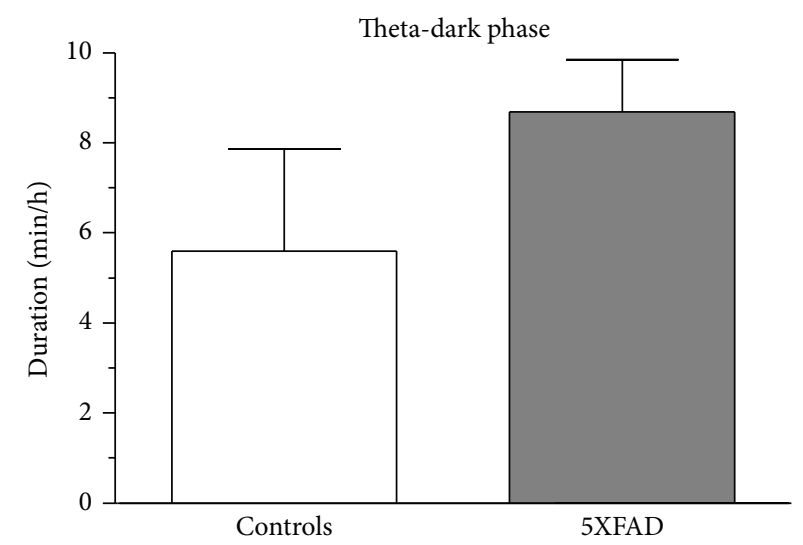

(c)

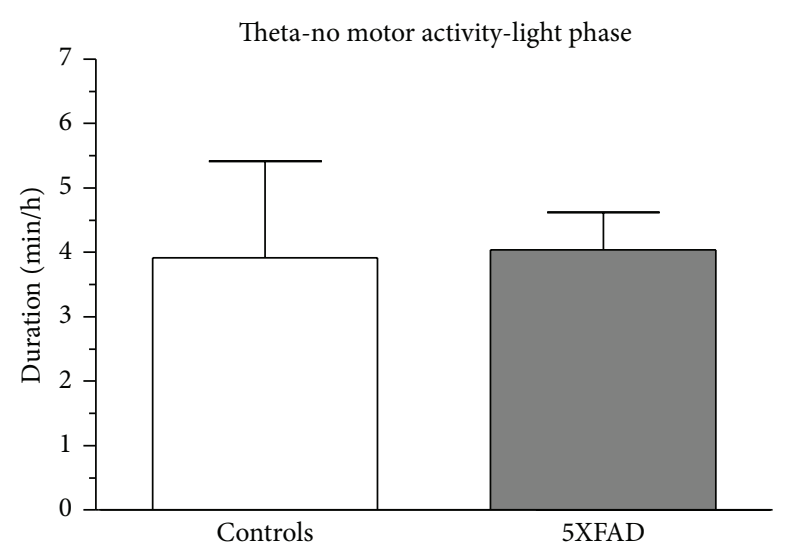

(e)

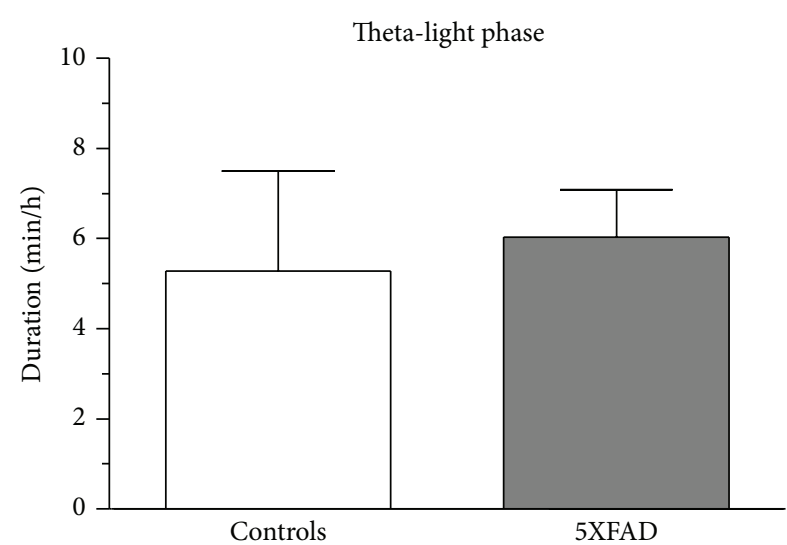

(b)

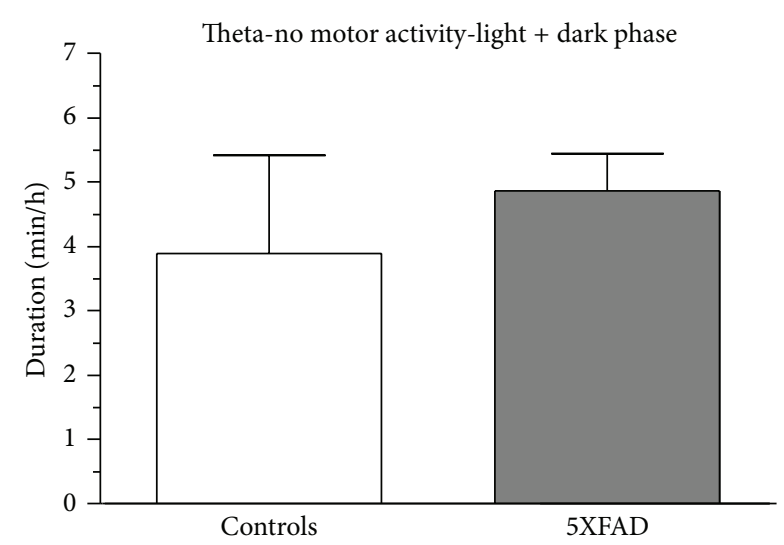

(d)

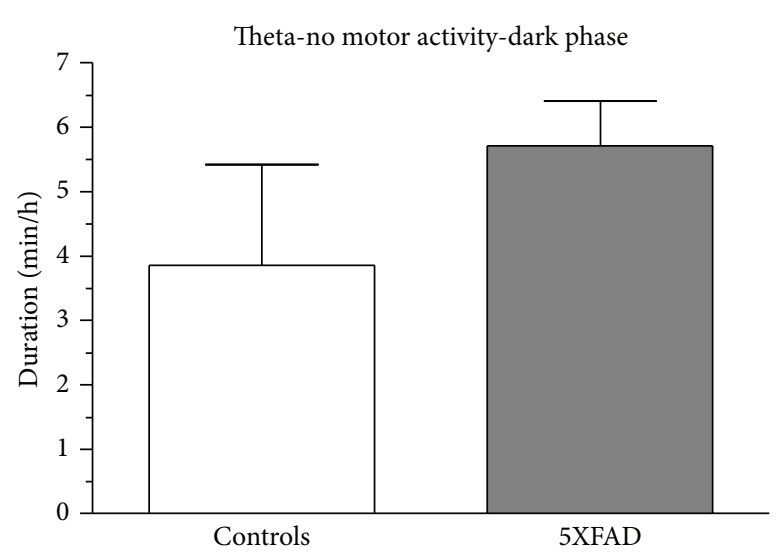

(f)

FIGURE 6: Characteristics of theta duration in control and 5XFAD mice. The theta-alpha band was analyzed using a time-frequency approach. Behavioral artefacts were removed using an algorithm as described above. Theta-segments (10 s) were summed to determine theta duration $(\mathrm{min} / \mathrm{h})$. Theta duration was calculated for both genotypes for the total observation period (a) and the light (b) and dark (c) phases, respectively. Total and phase-specific analysis was also done for nonmotor activity ((d)-(f)) and motor activity (not shown). Mean values suggest an increase in theta duration in 5XFAD mice, particularly during the dark phase ((c), (f)). 


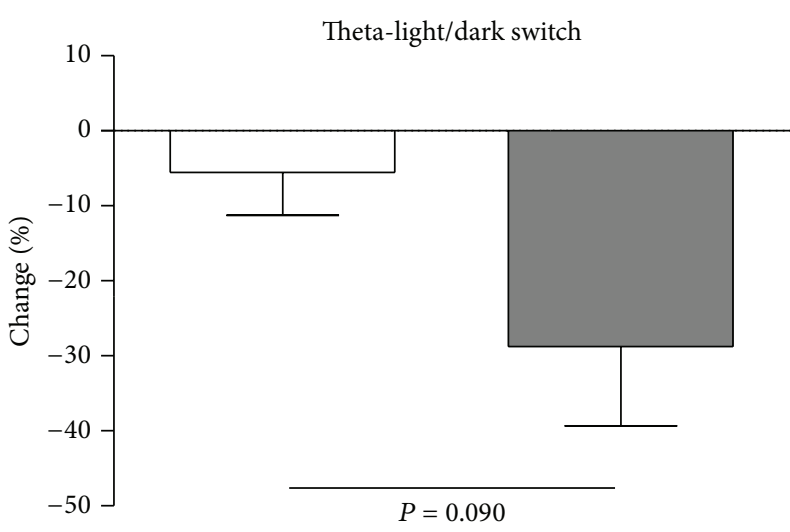

(a)

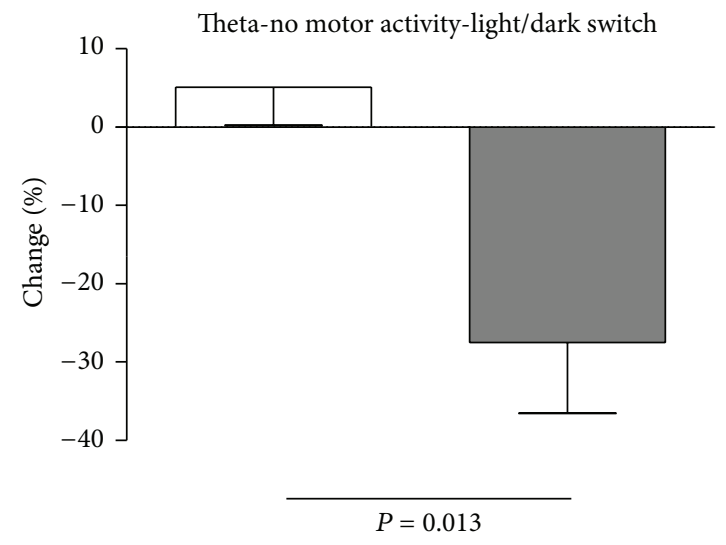

(b)

Figure 7: Percentage change in theta duration during light/dark switch. Data from Figures 6(b), 6(c), 6(e), and 6(f) were used to calculate the percentage change in theta duration for every individual mouse during the total observation period ( $48 \mathrm{~h}$, (a)), during nonmotor activity (b) and motor activity (not shown). During switch from light to dark cycle a statistic trend for theta duration increase turned out to exist in 5XFAD mice (a). Again, this effect was most prominent and significant during no motor activity (b) and absent during motor activity.

\section{Discussion}

Alzheimer's disease is a complex neurodegenerative disorder accompanied by cognitive impairment that ultimately leads to dementia. In the present study, we investigated transcriptional alterations and the EEG phenotype of 5XFAD mice. This mouse model harbors five early-onset FAD mutations and displays substantial amyloid plaques and neurodegeneration $[17,23]$. Our study demonstrates that 5XFAD mice exhibit nonconvulsive seizure activity of highly different severity, predominantly in the M1 deflection, whereas there was no seizure activity detectable in the CA1 recordings. It is noteworthy that $\mathrm{A} \beta$ formation in certain mouse models can differentially alter cholinergically induced rhythmicity according to the structure of $\mathrm{A} \beta$ plaques [17] and therefore resulting in variable seizure severity. In addition, stereological quantification of pyramidal neurons of the CA1 layer showed no significant difference between the number of neurons of WT and 5XFAD mice; however a significant loss was detected in cortical layer 5 [17]. Experimental studies in genetically engineered mice support these findings, highlighting the presence of subclinical seizures and overlapping pathophysiological cascades [72]. Reduced seizure thresholds and spontaneous convulsive seizure phenotypes have been observed in $\mathrm{AD}$ mouse models [73-76]. Interestingly, deletion of $\mathrm{A} \beta \mathrm{PP}$ [77] and BACE1, the secretase that participates in $\mathrm{A} \beta$ release [78], also causes an epileptic phenotype, indicating that normal $\mathrm{A} \beta \mathrm{PP}$ signaling is important for the development of hippocampal excitability [35]. In some models, lower thresholds for induced or spontaneous seizures are found even in the absence of amyloid deposits, further stressing the role of soluble forms of $\mathrm{A} \beta$ as a pathogen [76, 77]. Chronic EEG monitoring in J20 mice overexpressing hA $\beta$ PP [31] revealed that most frequent seizures were purely electroencephalographic, that is, nonconvulsive with complete motoric arrest as observed in our study using $5 \mathrm{XFAD}$ mice $[30,31]$.
In rare cases motor seizures were observed. This observation raises the question whether abnormal hippocampal neuronal synchronization might remain undetected in human $\mathrm{AD}$ patients and whether altered network activity might accelerate a more rapid cognitive decline in patients suffering from FAD [29, 31, 79]. Histological evaluation of the J20 mouse hippocampus revealed evidence for hippocampal network remodeling that is similar, but not identical, to the changes identified in both patients with temporal lobe epilepsy and experimental models of hippocampal seizures. The cellular changes included ectopic sprouting of dentate granule cell mossy fibres and sprouting of fibers containing the inhibitory neurotransmitter NPY [80, 81]. Convulsive seizures with associated hippocampal network plasticity have been confirmed in other $\mathrm{AD}$ mouse models $[35,82]$. Interestingly, impairment of GABA transmission in the J20 brain is likely to be responsible for epileptogenesis in these models. Increased adult neurogenesis is found in both human AD and TLE cases $[81,83]$. The multiple lines of evidence discussed above reveal that soluble forms of $\mathrm{A} \beta$ are cytotoxic inducing the appearance of aberrant excitatory neuronal network activity in vivo and triggering complex molecular and cellular patterns of compensatory inhibitory and excitatory mechanisms in the hippocampal circuitry [20, 43, 79, 84, 85].

The toxic accumulation of $\mathrm{A} \beta$ peptides underlying $\mathrm{AD}$ triggers synaptic degeneration, circuit remodeling, and abnormal synchronization within the same networks. Because neuronal hyperexcitability amplifies the synaptic release of $\mathrm{A} \beta$, seizures create a vicious spiral that accelerates cell death and cognitive decline in the AD brain [34]. While degenerative processes in the nervous system ultimately result in loss of neural signaling, when active inhibitory mechanisms fail early, the resulting disinhibition may destabilize network oscillatory activity at formative stages of the disease.

How can seizure activity correlate with altered theta oscillations in the hippocampus? Complex cognitive operations 
Theta-light + dark phase

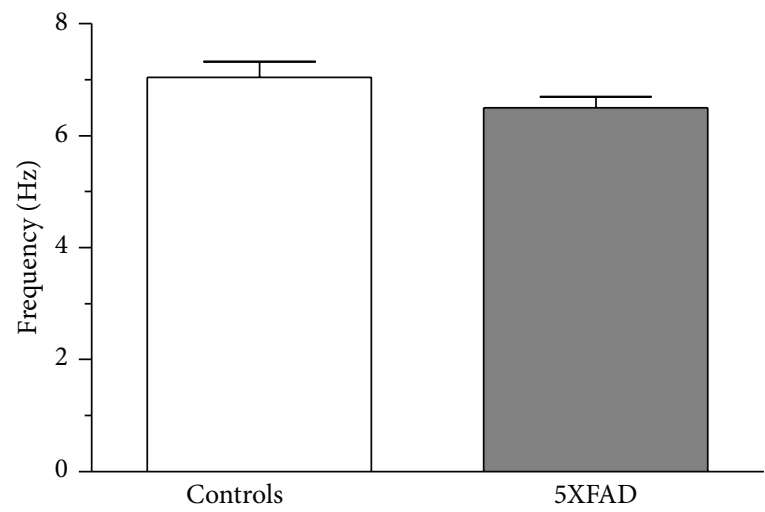

(a)

Theta-dark phase

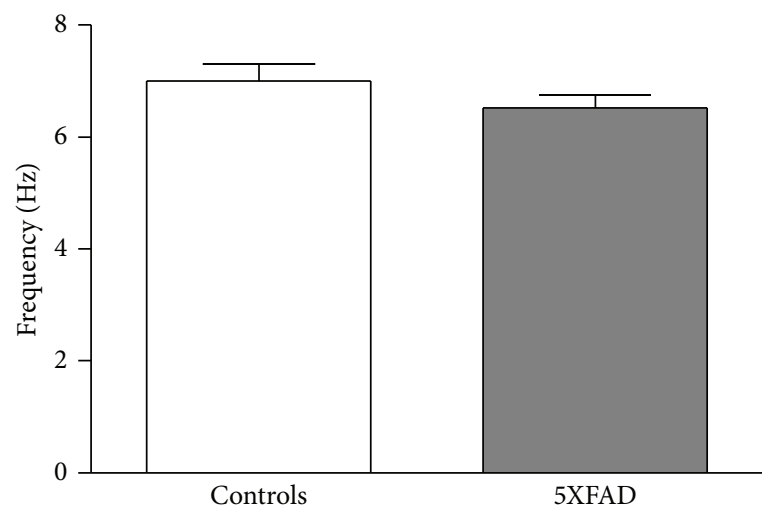

(c)

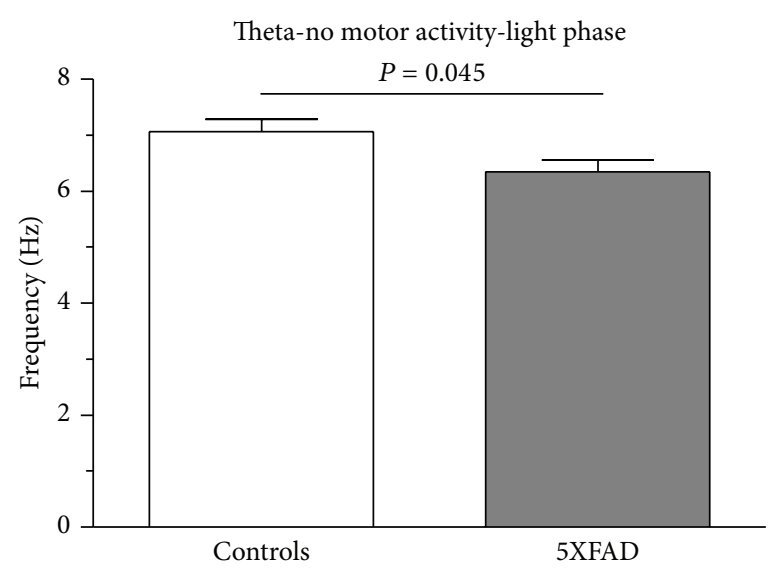

(e)

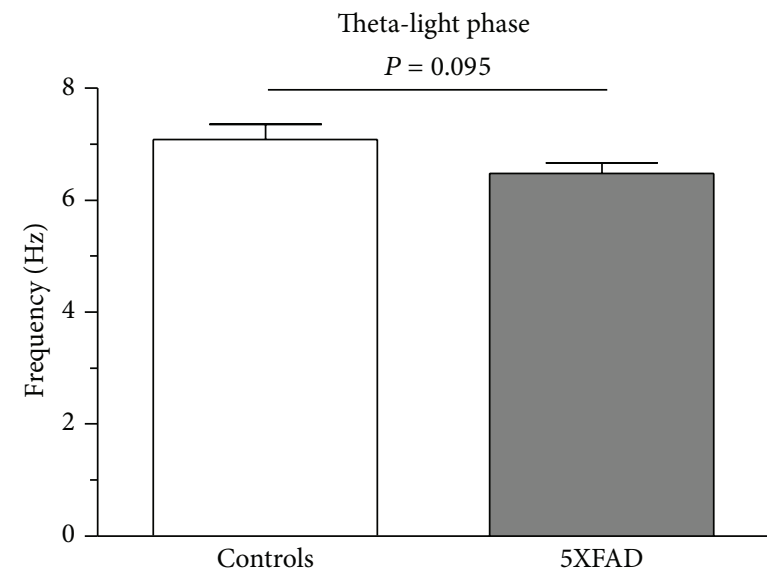

(b)

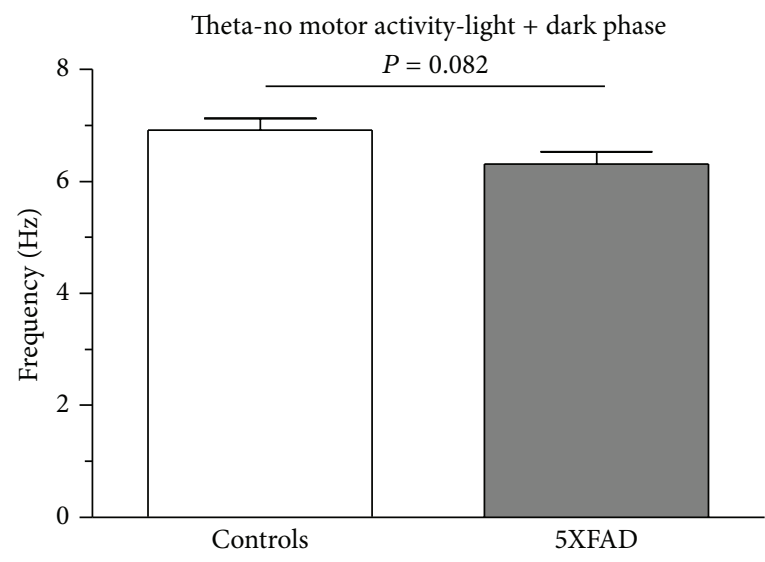

(d)

Theta-no motor activity-dark phase

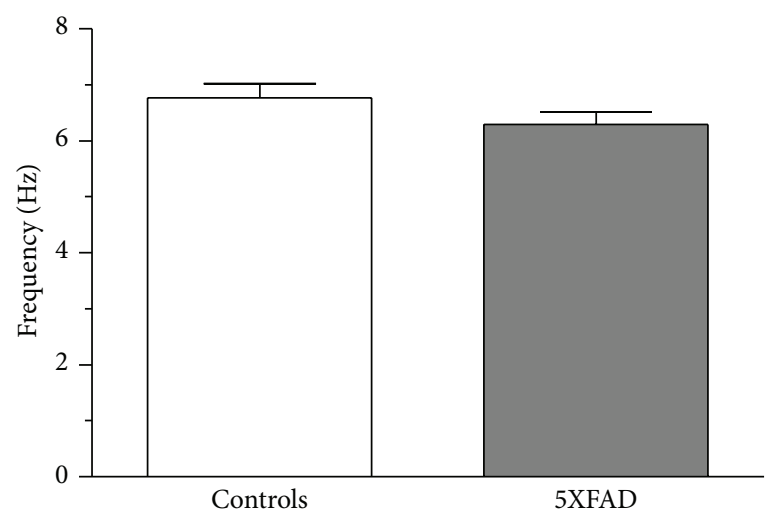

(f)

FIGURE 8: Theta frequency in controls and 5XFAD mice. The mean theta frequency was calculated for the total observation period (48 $\mathrm{h}$, (a)-(c)), no motor activity ((d)-(f)), and motor activity (not shown). In all cases, theta frequency is reduced. Again, this reduction turned out to be significant during no motor activity $(\mathrm{e})$. 


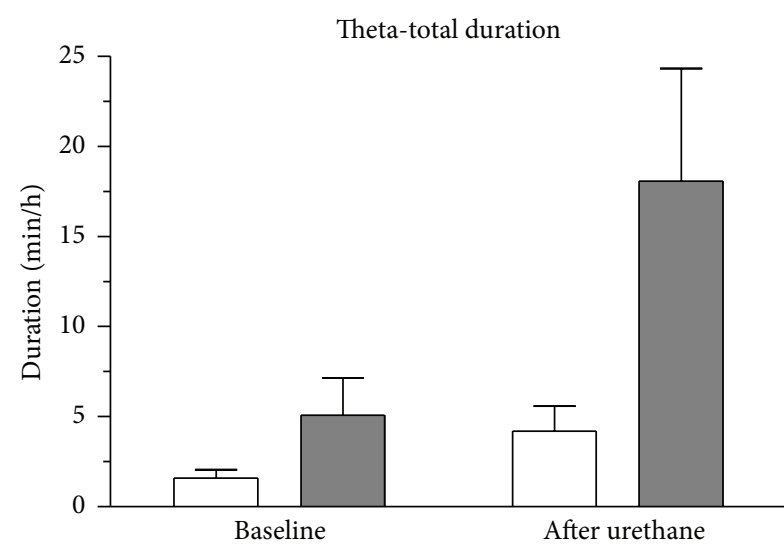

(a)

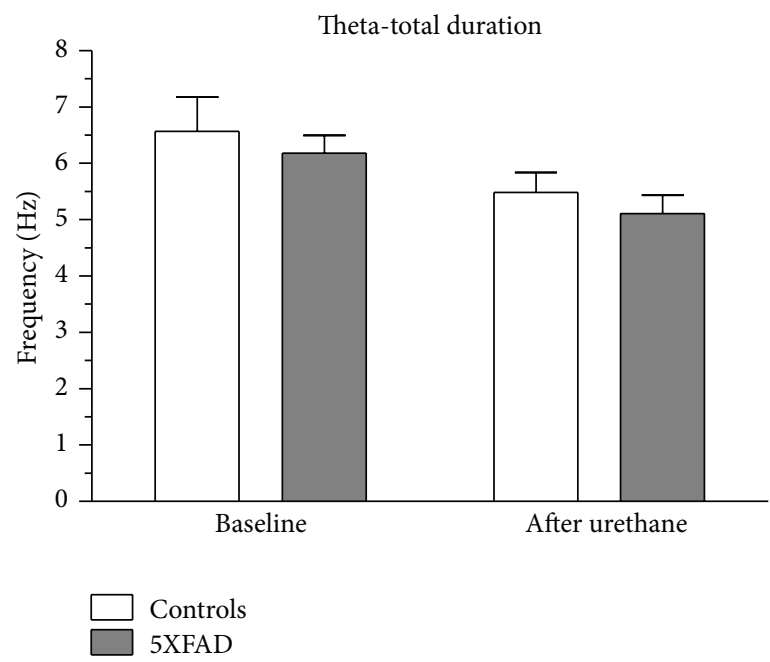

(c)

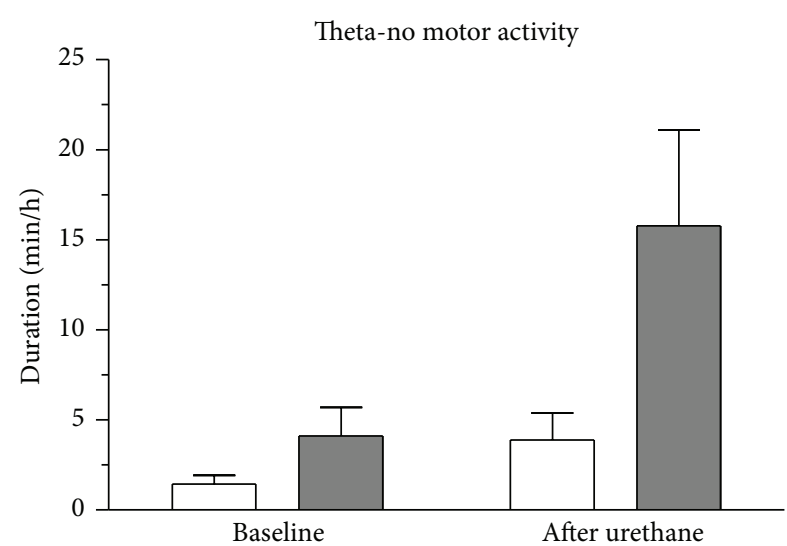

(b)

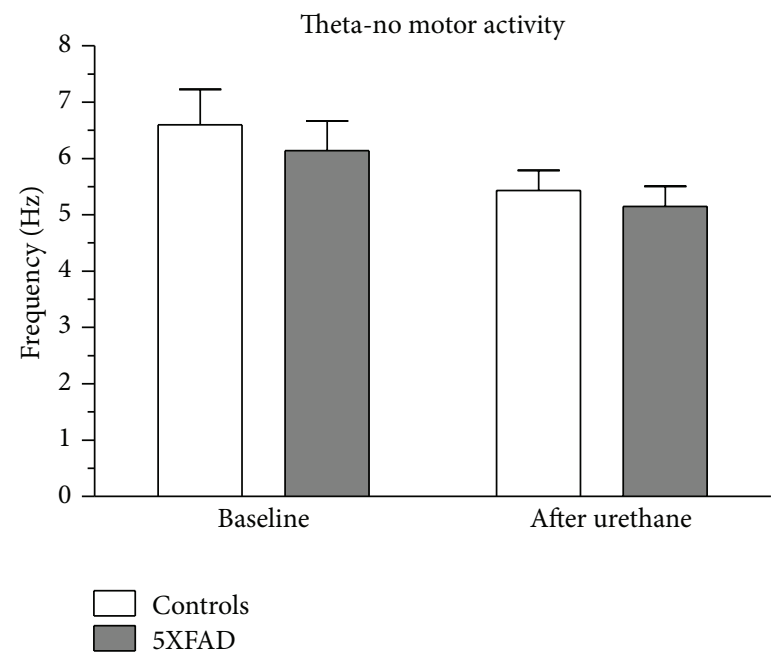

(d)

FIGURE 9: Urethane induced hippocampal theta oscillations in control and 5XFAD mice. CA1 hippocampal theta recordings from both genotypes were analyzed for duration of atropine-sensitive type II theta oscillations regarding total observation period (a) and nonmotor episodes (b). In addition, theta frequency was calculated for total duration (c) and nonmotor episodes (d).

depend on a sophisticated coordination of activity across a plethora of neuronal groups. One of the most intriguing mechanisms of neuronal coordination and communication is through neuronal synchronization by brain oscillations [86]. Theta oscillations represent one of these oscillations and are modulated by specific behavioral and cognitive states and are related to memory deficits, for example, in $\mathrm{AD}[31,32,34$, $49,56]$. Disruption of theta activity results in spatial memory deficits, whereas the restoration of theta-like rhythmicity restores learning capabilities in rats [87]. Theta duration analysis in our study suggests an increase of theta oscillations in 5XFAD mice during the dark phase. This phenomenon was most prominent during the switch from light to dark phase and nonmotor activity. As analysis of motor/nonmotor activity did not reveal any difference between controls and 5XFAD mice; the difference in theta duration is likely to be based on theta-subtype composition. We speculate that nonactive mice in the dark phase predominately exhibit alert-immobility which is accompanied by atropine-sensitive type II theta
$[88,89]$. As in our study, a statistical trend for an increase in theta duration has been described in the TgCRND8 mouse model [20]. These changes in theta duration in 5XFAD mice are an important variable because they are known to be associated with memory effectiveness. Animals displaying a higher amount of theta activity are faster in novel task learning than animals that exhibit less pronounced theta oscillations [90]. Unlike the common assumption of decreased theta activity in dementia, an increase in theta activity is observed in various mouse models of AD. Administration of urethane clearly proved that $5 \mathrm{XFAD}$ mice can exhibit increased atropine-sensitive type II theta oscillations upon provocation (Figures 9(a) and 9(b)). One might speculate that hyperexcitable neuronal clusters surrounded by degenerated neurons might account for this increase in theta which disrupts the ability of neuronal networks to dynamically adjust the amplitude of these oscillations during memory processes. Interestingly, the mean theta frequency was reduced in 5XFAD mice; that is, theta oscillations turned 
out to be significantly slower than in control animals. This phenomenon is commonly observed in $\mathrm{AD}$ patients [6871]. It has further been suggested that theta frequency could change as a function of novelty and familiarity [91]. Thus, the significant decrease in theta frequency could dramatically skew the delicate balance of theta frequency dynamics between novelty and familiarity.

Previous studies have shown that the muscarinic signal transduction cascade [92] is severely affected in AD [93] and this might correlate with a very slight downregulation of Plcb1 as observed in our study (Supplementary Figure 3). $\mathrm{Ca}_{\mathrm{v}} 2.3$ voltage-gated $\mathrm{Ca}^{2+}$ channels are involved in both the generation of cellular correlates of ictal discharges, that is, after depolarisation and plateau potentials [94, 95], and the generation of atropine-sensitive type II theta $[62,88,96$, 97]. Transcriptome analysis of $5 X F A D$ hippocampal probes performed in this study suggests an upregulation of $\mathrm{Plcd} 4$ which could result in type II theta acceleration via the PKC, $\mathrm{Ca}_{\mathrm{v}} 2.3$ cascade [62]; however, other muscarinic signaling targets could also be involved (Supplementary Figure 3).

Our study demonstrates that 5XFAD mice exhibit both nonconvulsive seizure activity and altered theta architecture, the latter being related to atropine-sensitive type II theta. Based on hippocampal microarray analysis we hypothesize that altered muscarinic signaling might play a role in the pathophysiology of both alteration. Although some caution is warranted in interpreting results from the aggressive 5XFAD model, our results support the view that pharmacological interference with muscarinic signaling is a potential valuable target in $\mathrm{AD}$ treatment. Finally, our study suggests that alterations in theta characteristics might serve as a diagnostic and prognostic biomarker in $\mathrm{AD}$ in the future.

\section{Abbreviations}

$\begin{array}{ll}\text { A } \beta: & \text { Amyloid- } \beta \\ \text { A } \beta \text { PP: } & \text { Amyloid- } \beta \text { precursor protein } \\ \text { AD: } & \text { Alzheimer's disease } \\ \text { BACE1: } & \beta \text {-site APP cleaving enzyme } 1 \\ \text { EEG: } & \text { Electroencephalogram } \\ \text { FAD: } & \text { Familial Alzheimer's disease } \\ \text { NFTs: } & \text { Neurofibrillary tangles } \\ \text { PSEN1: } & \text { Presenilin } 1 \\ \text { qPCR: } & \text { Quantitative real-time PCR } \\ \text { RMS: } & \text { Root mean square } \\ \text { SEM: } & \text { Standard error of the mean } \\ \text { WT: } & \text { Wild-type. }\end{array}$

\section{Conflict of Interests}

The authors declare that there is no conflict of interests regarding the publication of this paper.

\section{Authors' Contribution}

Magdalena Elisabeth Siwek and Ralf Müller contributed equally to this work.

\section{Acknowledgments}

The authors would like to thank Dr. Ylva Mende (German Center for Neurodegenerative Diseases, DZNE) and Dr. Michaela Moehring (DZNE) for assistance in animal breeding and animal health care. This work was financially supported by the Federal Institute for Drugs and Medical Devices (Bundesinstitut für Arzneimittel und Medizinprodukte, BfArM, Bonn, Germany).

\section{References}

[1] L. Scott, J. Feng, T. Kiss et al., "Age-dependent disruption in hippocampal theta oscillation in amyloid- $\beta$ overproducing transgenic mice," Neurobiology of Aging, vol. 33, no. 7, pp. 1481.e13-1481.e23, 2012.

[2] H. Yamaguchi, S. Hirai, M. Morimatsu, M. Shoji, and Y. Nakazato, "Diffuse type of senile plaques in the cerebellum of Alzheimer-type dementia demonstrated by $\beta$ protein immunostain," Acta Neuropathologica, vol. 77, no. 3, pp. 314-319, 1989.

[3] D. J. Selkoe, "Alzheimer's disease is a synaptic failure," Science, vol. 298, no. 5594, pp. 789-791, 2002.

[4] D. J. Selkoe and D. Schenk, "Alzheimer's disease: molecular understanding predicts amyloid-based therapeutics," Annual Review of Pharmacology and Toxicology, vol. 43, pp. 545-584, 2003.

[5] K. H. Ashe, "Learning and memory in transgenic mice modeling Alzheimer's disease," Learning and Memory, vol. 8, no. 6, pp. 301-308, 2001.

[6] J. L. Eriksen and C. G. Janus, "Plaques, tangles, and memory loss in mouse models of neurodegeneration," Behavior Genetics, vol. 37, no. 1, pp. 79-100, 2007.

[7] G. G. Glenner and C. W. Wong, "Alzheimer's disease: initial report of the purification and characterization of a novel cerebrovascular amyloid protein," Biochemical and Biophysical Research Communications, vol. 120, no. 3, pp. 885-890, 1984.

[8] G. G. Glenner, C. W. Wong, V. Quaranta, and E. D. Eanes, “The amyloid deposits in Alzheimer's disease: their nature and pathogenesis," Applied Pathology, vol. 2, no. 6, pp. 357-369, 1984.

[9] M. Ohno, S. L. Cole, M. Yasvoina et al., "BACE1 gene deletion prevents neuron loss and memory deficits in 5XFAD APP/PS1 transgenic mice," Neurobiology of Disease, vol. 26, no. 1, pp. 134$145,2007$.

[10] K. Duff and F. Suleman, "Transgenic mouse models of Alzheimer's disease: how useful have they been for therapeutic development?" Briefings in Functional Genomics \& Proteomics, vol. 3, no. 1, pp. 47-59, 2004.

[11] I. Torres-Aleman, "Toward a comprehensive neurobiology of IGF-I,” Developmental Neurobiology, vol. 70, no. 5, pp. 384-396, 2010.

[12] L. Devi and M. Ohno, "Deletion of the eIF2 $\alpha$ kinase GCN2 fails to rescue the memory decline associated with Alzheimer's disease," PLoS ONE, vol. 8, no. 10, Article ID e77335, 2013.

[13] S. Sinha, J. P. Anderson, R. Barbour et al., "Purification and cloning of amyloid precursor protein $\beta$-secretase from human brain," Nature, vol. 402, no. 6761, pp. 537-540, 1999.

[14] R. Vassar, B. D. Bennett, S. Babu-Khan et al., “ $\beta$-Secretase cleavage of Alzheimer's amyloid precursor protein by the transmembrane aspartic protease BACE," Science, vol. 286, no. 5440, pp. 735-741, 1999. 
[15] H. Oakley, S. L. Cole, S. Logan et al., "Intraneuronal $\beta$-amyloid aggregates, neurodegeneration, and neuron loss in transgenic mice with five familial Alzheimer's disease mutations: potential factors in amyloid plaque formation," The Journal of Neuroscience, vol. 26, no. 40, pp. 10129-10140, 2006.

[16] M. Ohno, E. A. Sametsky, L. H. Younkin et al., "BACE1 deficiency rescues memory deficits and cholinergic dysfunction in a mouse model of Alzheimer's disease," Neuron, vol. 41, no. 1, pp. 27-33, 2004.

[17] N. Crouzin, K. Baranger, M. Cavalier et al., "Area-specific alterations of synaptic plasticity in the 5XFAD mouse model of Alzheimer's disease: dissociation between somatosensory cortex and hippocampus," PLoS ONE, vol. 8, no. 9, Article ID e74667, 2013.

[18] D. Games, D. Adams, R. Alessandrini et al., "Alzheimer-type neuropathology in transgenic mice overexpressing V717F $\beta$ amyloid precursor protein," Nature, vol. 373 , no. 6514, pp. 523527, 1995.

[19] E. M. Rockenstein, L. McConlogue, H. Tan, M. Power, E. Masliah, and L. Mucke, "Levels and alternative splicing of amyloid $\beta$ protein precursor (APP) transcripts in brains of APP transgenic mice and humans with Alzheimer's disease," The Journal of Biological Chemistry, vol. 270, no. 47, pp. 28257-28267, 1995.

[20] R. Goutagny and S. Krantic, "Hippocampal oscillatory activity in Alzheimer's disease: toward the identification of early biomarkers?" Aging and Disease, vol. 4, no. 3, pp. 134-140, 2013.

[21] S. Jawhar, A. Trawicka, C. Jenneckens, T. A. Bayer, and O. Wirths, "Motor deficits, neuron loss, and reduced anxiety coinciding with axonal degeneration and intraneuronal $\mathrm{A} \beta$ aggregation in the 5XFAD mouse model of Alzheimer's disease," Neurobiology of Aging, vol. 33, no. 1, pp. 196.e29-196.e40, 2012.

[22] C. Casas, N. Sergeant, J.-M. Itier et al., "Massive CA1/2 neuronal loss with intraneuronal and N-terminal truncated Abeta 42 accumulation in a novel Alzheimer transgenic model," The American Journal of Pathology, vol. 165, no. 4, pp. 1289-1300, 2004.

[23] W. A. Eimer and R. Vassar, "Neuron loss in the 5XFAD mouse model of Alzheimer's disease correlates with intraneuronal Abeta42 accumulation and Caspase-3 activation," Molecular Neurodegeneration, vol. 8, article 29, 2013.

[24] C. C. Kaczorowski and J. F. Disterhoft, "Memory deficits are associated with impaired ability to modulate neuronal excitability in middle-aged mice," Learning and Memory, vol. 16, no. 6, pp. 362-366, 2009.

[25] I. Hong, T. Kang, Y. Yoo et al., "Quantitative proteomic analysis of the hippocampus in the 5XFAD mouse model at early stages of Alzheimer's disease pathology," Journal of Alzheimer's Disease, vol. 36, no. 2, pp. 321-334, 2013.

[26] K. H. Kim, M. Moon, S.-B. Yu, I. Mook-Jung, and J.-I. Kim, "RNA-Seq analysis of frontal cortex and cerebellum from 5XFAD mice at early stage of disease pathology," Journal of Alzheimer's Disease, vol. 29, no. 4, pp. 793-808, 2012.

[27] P. J. Blanchet, "Antipsychotic drug-induced movement disorders," Canadian Journal of Neurological Sciences, vol. 30, supplement 1, pp. S101-S107, 2003.

[28] D. Martino and G. Giovannoni, "Antibasal ganglia antibodies and their relevance to movement disorders," Current Opinion in Neurology, vol. 17, no. 4, pp. 425-432, 2004.

[29] J. J. Palop, J. Chin, and L. Mucke, "A network dysfunction perspective on neurodegenerative diseases," Nature, vol. 443, no. 7113, pp. 768-773, 2006.
[30] J. J. Palop and L. Mucke, "Epilepsy and cognitive impairments in alzheimer disease," Archives of Neurology, vol. 66, no. 4, pp. 435-440, 2009.

[31] J. J. Palop, J. Chin, E. D. Roberson et al., "Aberrant excitatory neuronal activity and compensatory remodeling of inhibitory hippocampal circuits in mouse models of Alzheimer's disease," Neuron, vol. 55, no. 5, pp. 697-711, 2007.

[32] G. Buzsáki, “Theta oscillations in the hippocampus," Neuron, vol. 33, no. 3, pp. 325-340, 2002.

[33] L. V. Colom, "Septal networks: relevance to theta rhythm, epilepsy and Alzheimer's disease," Journal of Neurochemistry, vol. 96, no. 3, pp. 609-623, 2006.

[34] J. Chin and H. E. Scharfman, "Shared cognitive and behavioral impairments in epilepsy and Alzheimer's disease and potential underlying mechanisms," Epilepsy and Behavior, vol. 26, no. 3, pp. 343-351, 2013.

[35] R. Minkeviciene, S. Rheims, M. B. Dobszay et al., "Amyloid induced neuronal hyperexcitability triggers progressive epilepsy-induced neuronal hyperexcitability triggers progressive epilepsy," The Journal of Neuroscience, vol. 29, no. 11, pp. 3453$3462,2009$.

[36] L. Verret, E. O. Mann, G. B. Hang et al., "Inhibitory interneuron deficit links altered network activity and cognitive dysfunction in Alzheimer model," Cell, vol. 149, no. 3, pp. 708-721, 2012.

[37] M. F. Mendez and G. T. H. Lim, "Seizures in elderly patients with dementia: epidemiology and management," Drugs and Aging, vol. 20, no. 11, pp. 791-803, 2003.

[38] A. J. Larner, "Epileptic seizures in AD patients," NeuroMolecular Medicine, vol. 12, no. 1, pp. 71-77, 2010.

[39] N. Scarmeas, L. S. Honig, H. Choi et al., "Seizures in Alzheimer disease: who, when, and how common?" Archives of Neurology, vol. 66, no. 8, pp. 992-997, 2009.

[40] J. H. Morrison and P. R. Hof, "Life and death of neurons in the aging brain," Science, vol. 278, no. 5337, pp. 412-419, 1997.

[41] J. L. Price, A. I. Ko, M. J. Wade, S. K. Tsou, D. W. McKeel, and J. C. Morris, "Neuron number in the entorhinal cortex and CA1 in preclinical alzheimer disease," Archives of Neurology, vol. 58, no. 9, pp. 1395-1402, 2001.

[42] R. D. Terry, E. Masliah, D. P. Salmon et al., "Physical basis of cognitive alterations in Alzheimer's disease: synapse loss is the major correlate of cognitive impairment," Annals of Neurology, vol. 30, no. 4, pp. 572-580, 1991.

[43] W. A. Hauser, M. L. Morris, L. L. Heston, and V. E. Anderson, "Seizures and myoclonus in patients with Alzheimer's disease," Neurology, vol. 36, no. 9, pp. 1226-1230, 1986.

[44] M. F. Romanelli, J. C. Morris, K. Ashkin, and L. A. Coben, "Advanced Alzheimer's disease is a risk factor for late-onset seizures," Archives of Neurology, vol. 47, no. 8, pp. 847-850, 1990.

[45] D. S. Auld, T. J. Kornecook, S. Bastianetto, and R. Quirion, "Alzheimer's disease and the basal forebrain cholinergic system: relations to $\beta$-amyloid peptides, cognition, and treatment strategies," Progress in Neurobiology, vol. 68, no. 3, pp. 209-245, 2002.

[46] K. M. Cullen, "Perivascular astrocytes within Alzheimer's disease plaques," NeuroReport, vol. 8, no. 8, pp. 1961-1966, 1997.

[47] J. Pálhalmi, O. Paulsen, T. F. Freund, and N. Hájos, "Distinct properties of carbachol- and DHPG-induced network oscillations in hippocampal slices," Neuropharmacology, vol. 47, no. 3, pp. 381-389, 2004. 
[48] C. G. Reich, M. A. Karson, S. V. Karnup, L. M. Jones, and B. E. Alger, "Regulation of IPSP theta rhythm by muscarinic receptors and endocannabinoids in hippocampus," Journal of Neurophysiology, vol. 94, no. 6, pp. 4290-4299, 2005.

[49] A. I. Gutiérrez-Lerma, B. Ordaz, and F. Peña-Ortega, "Amyloid beta peptides differentially affect hippocampal theta rhythms in vitro," International Journal of Peptides, vol. 2013, Article ID 328140, 11 pages, 2013.

[50] Y. Ikarashi, Y. Harigaya, Y. Tomidokoro et al., "Decreased level of brain acetylcholine and memory disturbance in APPsw mice," Neurobiology of Aging, vol. 25, no. 4, pp. 483-490, 2004.

[51] M. Klingner, J. Apelt, A. Kumar et al., "Alterations in cholinergic and non-cholinergic neurotransmitter receptor densities in transgenic Tg2576 mouse brain with $\beta$-amyloid plaque pathology," International Journal of Developmental Neuroscience, vol. 21, no. 7, pp. 357-369, 2003.

[52] J. H. Kordower, Y. Chu, G. T. Stebbins et al., "Loss and atrophy of layer II entorhinal cortex neurons in elderly people with mild cognitive impairment," Annals of Neurology, vol. 49, no. 2, pp. 202-213, 2001.

[53] H.-J. Lüth, J. Apelt, A. O. Ihunwo, T. Arendt, and R. Schliebs, "Degeneration of $\beta$-amyloid-associated cholinergic structures in transgenic $\mathrm{APP}_{S W}$ mice," Brain Research, vol. 977, no. 1, pp. 16-22, 2003.

[54] C. Babiloni, G. B. Frisoni, M. Pievani et al., "White matter vascular lesions are related to parietal-to-frontal coupling of EEG rhythms in mild cognitive impairment," Human Brain Mapping, vol. 29, no. 12, pp. 1355-1367, 2008.

[55] T. D. R. Cummins, M. Broughton, and S. Finnigan, "Theta oscillations are affected by amnestic mild cognitive impairment and cognitive load," International Journal of Psychophysiology, vol. 70, no. 1, pp. 75-81, 2008.

[56] F. Peña-Ortega and R. Bernal-Pedraza, "Amyloid beta peptide slows down sensory-induced hippocampal oscillations," International Journal of Peptides, vol. 2012, Article ID 236289, 8 pages, 2012.

[57] C. Babiloni, E. Cassetta, G. Binetti et al., "Resting EEG sources correlate with attentional span in mild cognitive impairment and Alzheimer's disease," European Journal of Neuroscience, vol. 25, no. 12, pp. 3742-3757, 2007.

[58] M. Weiergräber, M. Henry, J. Hescheler, N. Smyth, and T. Schneider, "Electrocorticographic and deep intracerebral EEG recording in mice using a telemetry system," Brain Research Protocols, vol. 14, no. 3, pp. 154-164, 2005.

[59] K. Kramer and L. B. Kinter, "Evaluation and applications of radiotelemetry in small laboratory animals," Physiological Genomics, vol. 13, no. 3, pp. 197-205, 2003.

[60] R. Kronland-Martinet, J. Morlet, and A. Grossmann, "Analysis of sound patterns through wavelet transforms," International Journal of Pattern Recognition and Artificial Intelligence, vol. 1, no. 2, pp. 273-302, 1987.

[61] S. M. Montgomery and G. Buzsáki, "Gamma oscillations dynamically couple hippocampal CA3 and CA1 regions during memory task performance," Proceedings of the National Academy of Sciences of the United States of America, vol. 104, no. 36, pp. 14495-14500, 2007.

[62] R. Müller, H. Struck, M. S. P. Ho et al., "Atropine-sensitive hippocampal theta oscillations are mediated by $\mathrm{Ca}_{v} 2.3 \mathrm{R}$-type $\mathrm{Ca}^{2+}$ channels," Neuroscience, vol. 205, pp. 125-139, 2012.
[63] D. W. Huang, B. T. Sherman, and R. A. Lempicki, "Systematic and integrative analysis of large gene lists using DAVID bioinformatics resources," Nature Protocols, vol. 4, no. 1, pp. 44-57, 2009.

[64] D. W. Huang, B. T. Sherman, and R. A. Lempicki, "Bioinformatics enrichment tools: paths toward the comprehensive functional analysis of large gene lists," Nucleic Acids Research, vol. 37, no. 1, pp. 1-13, 2009.

[65] T. D. Schmittgen and K. J. Livak, "Analyzing real-time PCR data by the comparative CT method," Nature Protocols, vol. 3, no. 6, pp. 1101-1108, 2008.

[66] Y. Hochberg, "A sharper Bonferroni procedure for multiple tests of significance," Biometrika, vol. 75, no. 4, pp. 800-802, 1988.

[67] M. A. Burguillos, T. Deierborg, E. Kavanagh et al., "Caspase signalling controls microglia activation and neurotoxicity," Nature, vol. 472, no. 7343, pp. 319-324, 2011.

[68] V. Jelic, S.-E. Johansson, O. Almkvist et al., "Quantitative electroencephalography in mild cognitive impairment: longitudinal changes and possible prediction of Alzheimer's disease," Neurobiology of Aging, vol. 21, no. 4, pp. 533-540, 2000.

[69] K. van der Hiele, A. A. Vein, A. van der Welle et al., "EEG and MRI correlates of mild cognitive impairment and Alzheimer's disease," Neurobiology of Aging, vol. 28, no. 9, pp. 1322-1329, 2007.

[70] B. Czigler, D. Csikós, Z. Hidasi et al., "Quantitative EEG in early Alzheimer's disease patients-power spectrum and complexity features," International Journal of Psychophysiology, vol. 68, no. 1, pp. 75-80, 2008.

[71] V. D. Moretti, M. Pievani, C. Geroldi et al., "EEG markers discriminate among different subgroup of patients with mild cognitive impairment," American Journal of Alzheimer's Disease and Other Dementias, vol. 25, no. 1, pp. 58-73, 2010.

[72] J. Noebels, "A perfect storm: converging paths of epilepsy and Alzheimer's dementia intersect in the hippocampal formation," Epilepsia, vol. 52, supplement 1, pp. 39-46, 2011.

[73] F. M. LaFerla, B. T. Tinkle, C. J. Bieberich, C. C. Haudenschild, and G. Jay, "The Alzheimer's A $\beta$ peptide induces neurodegeneration and apoptotic cell death in transgenic mice," Nature Genetics, vol. 9, no. 1, pp. 21-30, 1995.

[74] R. Lalonde, M. Dumont, M. Staufenbiel, and C. Strazielle, "Neurobehavioral characterization of APP23 transgenic mice with the SHIRPA primary screen," Behavioural Brain Research, vol. 157, no. 1, pp. 91-98, 2005.

[75] D. Moechars, K. Lorent, B. de Strooper, I. Dewachter, and F. Van Leuven, "Expression in brain of amyloid precursor protein mutated in the $\alpha$-secretase site causes disturbed behavior, neuronal degeneration and premature death in transgenic mice," The EMBO Journal, vol. 15, no. 6, pp. 1265-1274, 1996.

[76] V. B. Kumar, S. A. Farr, J. F. Flood et al., "Site-directed antisense oligonucleotide decreases the expression of amyloid precursor protein and reverses deficits in learning and memory in aged SAMP8 mice," Peptides, vol. 22, no. 12, pp. 1769-1775, 2000.

[77] J. P. Steinbach, U. Müller, M. Leist, Z.-W. Li, P. Nicotera, and A. Aguzzi, "Hypersensitivity to seizures in $\beta$-amyloid precursor protein deficient mice," Cell Death \& Differentiation, vol. 5, no. 10, pp. 858-866, 1998.

[78] Y.-S. Hu, P. Xu, G. Pigino, S. T. Brady, J. Larson, and O. Lazarov, "Complex environment experience rescues impaired neurogenesis, enhances synaptic plasticity, and attenuates neuropathology in familial Alzheimer's disease-linked APPswe/PS1 $\triangle \mathrm{E} 9$ mice," The FASEB Journal, vol. 24, no. 6, pp. 1667-1681, 2010. 
[79] D. Pandis and N. Scarmeas, "Seizures in alzheimer disease: clinical and epidemiological data," Epilepsy Currents, vol. 12, no. 5, pp. 184-187, 2012.

[80] N. C. de Lanerolle, J. H. Kim, R. J. Robbins, and D. D. Spencer, "Hippocampal interneuron loss and plasticity in human temporal lobe epilepsy," Brain Research, vol. 495, no. 2, pp. 387-395, 1989.

[81] T. Sutula, G. Cascino, J. Cavazos, I. Parada, and L. Ramirez, "Mossy fiber synaptic reorganization in the epileptic human temporal lobe," Annals of Neurology, vol. 26, no. 3, pp. 321-330, 1989.

[82] R. Minkeviciene, J. Ihalainen, T. Malm et al., "Age-related decrease in stimulated glutamate release and vesicular glutamate transporters in APP/PS1 transgenic and wild-type mice," Journal of Neurochemistry, vol. 105, no. 3, pp. 584-594, 2008.

[83] K. Jin, A. L. Peel, X. O. Mao et al., "Increased hippocampal neurogenesis in Alzheimer's disease," Proceedings of the National Academy of Sciences of the United States of America, vol. 101, no. 1, pp. 343-347, 2004.

[84] J. C. Amatniek, W. A. Hauser, C. DelCastillo-Castaneda et al., "Incidence and predictors of seizures in patients with Alzheimer's disease," Epilepsia, vol. 47, no. 5, pp. 867-872, 2006.

[85] C. J. Westmark, P. R. Westmark, A. M. Beard, S. M. Hildebrandt, and J. S. Malter, "Seizure susceptibility and mortality in mice that over-express amyloid precursor protein," International Journal of Clinical and Experimental Pathology, vol. 1, no. 2, pp. 157-168, 2008.

[86] T. Womelsdorf, J.-M. Schoffelen, R. Oostenveld et al., "Modulation of neuronal interactions through neuronal synchronization," Science, vol. 316, no. 5831, pp. 1609-1612, 2007.

[87] N. McNaughton, M. Ruan, and M.-A. Woodnorth, "Restoring theta-like rhythmicity in rats restores initial learning in the Morris water maze," Hippocampus, vol. 16, no. 12, pp. 1102-1110, 2006.

[88] J. Shin, D. Kim, R. Bianchi, R. K. S. Wong, and H.-S. Shin, "Genetic dissection of theta rhythm heterogeneity in mice," Proceedings of the National Academy of Sciences of the United States of America, vol. 102, no. 50, pp. 18165-18170, 2005.

[89] B. H. Bland, C. Trepel, S. D. Oddie, and I. J. Kirk, "Intraseptal microinfusion of muscimol: effects on hippocampal formation theta field activity and phasic Theta-ON cell discharges," Experimental Neurology, vol. 138, no. 2, pp. 286-297, 1996.

[90] S. D. Berry, P. C. Rinaldi, R. F. Thompson, and M. Verzeano, "Analysis of temporal relations among units and slow waves in rabbit hippocampus," Brain Research Bulletin, vol. 3, no. 5, pp. 509-518, 1978.

[91] A. Jeewajee, C. Lever, S. Burton, J. O'Keefe, and N. Burgess, "Environmental novelty is signaled by reduction of the hippocampal theta frequency," Hippocampus, vol. 18, no. 4, pp. 340348, 2008.

[92] C. C. Felder, "Muscarinic acetylcholine receptors: signal transduction through multiple effectors," The FASEB Journal, vol. 9, no. 8, pp. 619-625, 1995.

[93] H.-M. Huang, H.-C. Ou, and S.-J. Hsieh, "Amyloid beta peptide impaired carbachol but not glutamate-mediated phosphoinositide pathways in cultured rat cortical neurons," Neurochemical Research, vol. 25, no. 2, pp. 303-312, 2000.

[94] J. B. Kuzmiski, W. Barr, G. W. Zamponi, and B. A. MacVicar, "Topiramate inhibits the initiation of plateau potentials in CA1 neurons by depressing R-type calcium channels," Epilepsia, vol. 46, no. 4, pp. 481-489, 2005.
[95] C. Tai, J. B. Kuzmiski, and B. A. MacVicar, "Muscarinic enhancement of R-type calcium currents in hippocampal CA1 pyramidal neurons," The Journal of Neuroscience, vol. 26, no. 23, pp. 6249-6258, 2006.

[96] J. Shin, G. Gireesh, S.-W. Kim et al., "Phospholipase C $\beta 4$ in the medial septum controls cholinergic theta oscillations and anxiety behaviors," The Journal of Neuroscience, vol. 29, no. 49, pp. 15375-15385, 2009.

[97] R. Jansen, J. Timmerman, M. Loos et al., "Novel candidate genes associated with hippocampal oscillations," PLoS ONE, vol. 6, no. 10, Article ID e26586, 2011. 

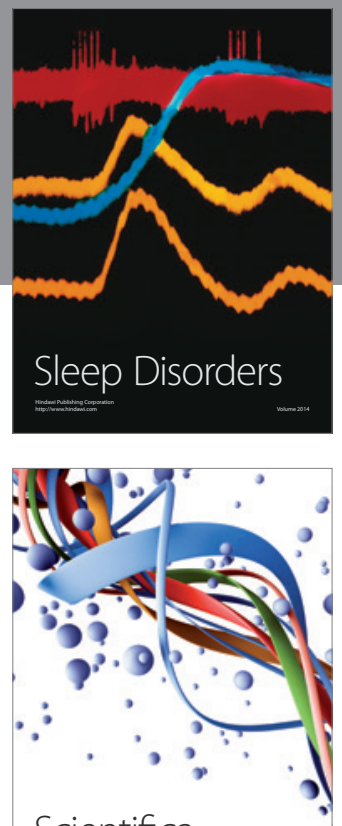

Scientifica
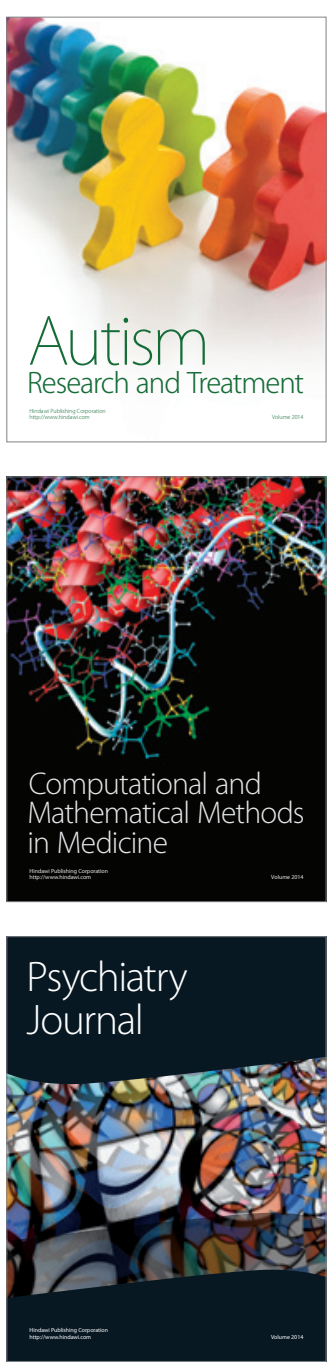
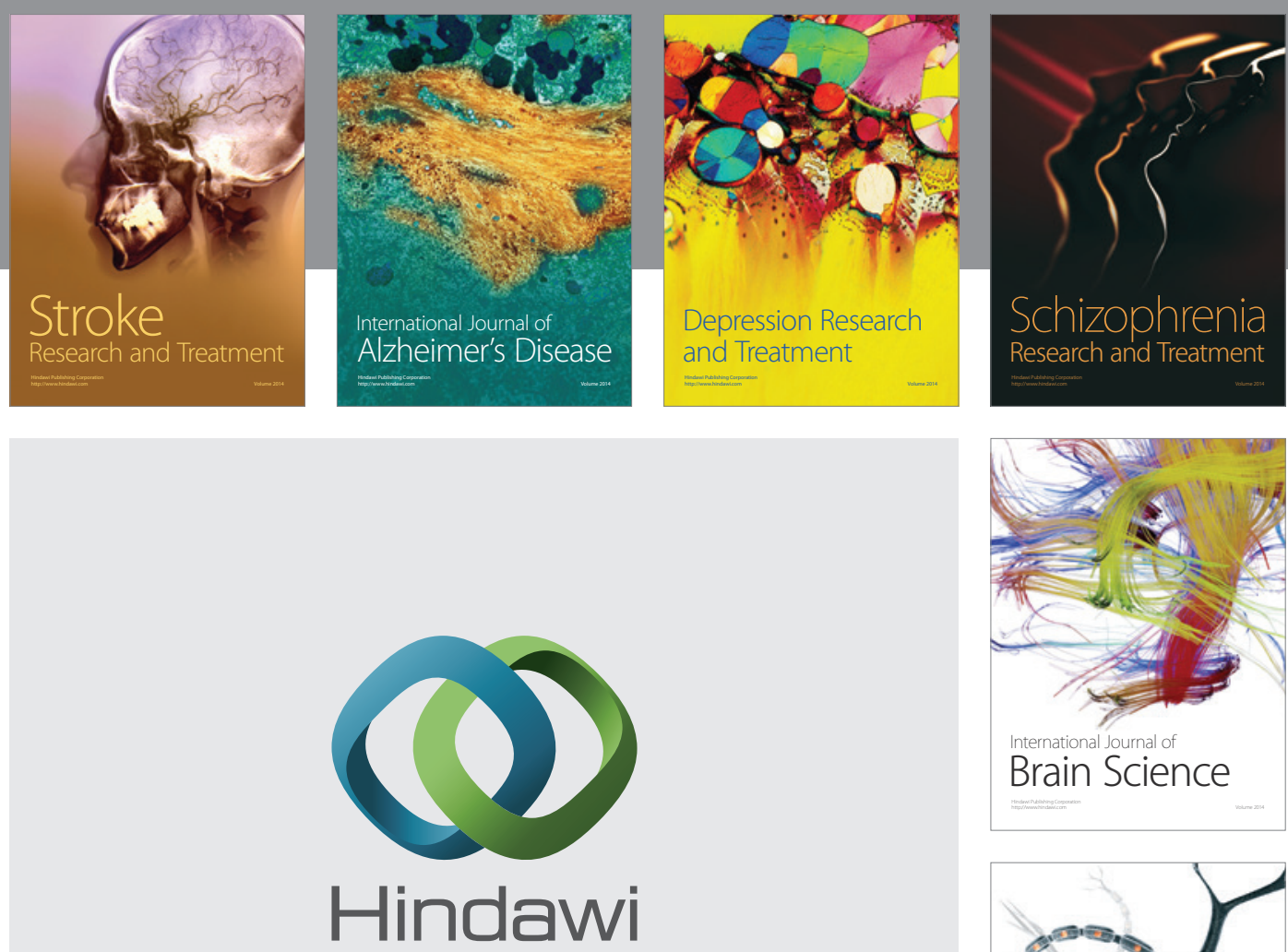

Submit your manuscripts at

http://www.hindawi.com
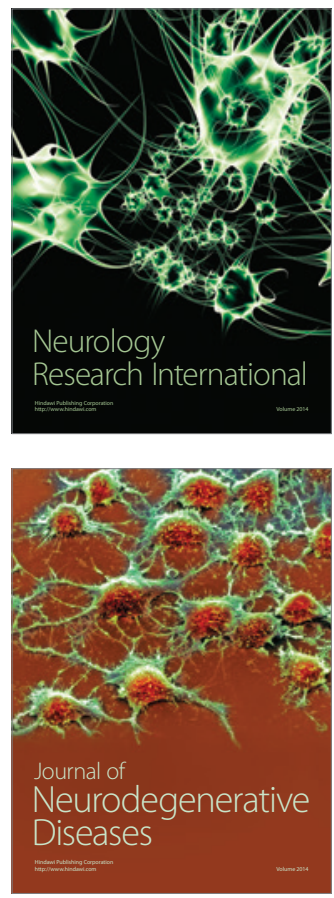

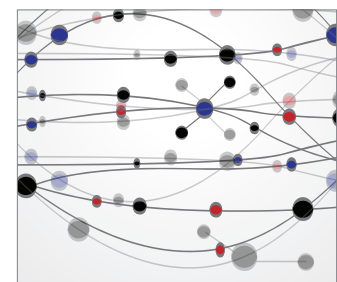

The Scientific World Journal
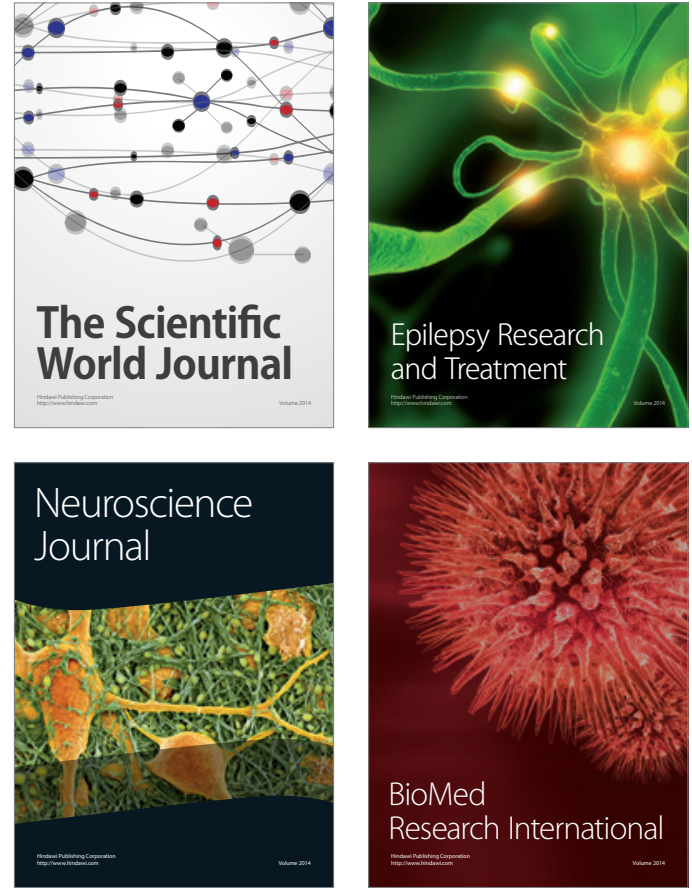

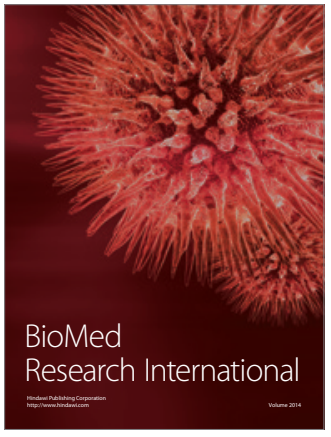

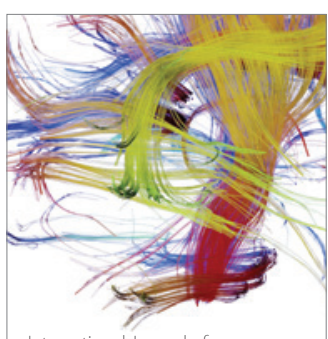

Brain Science

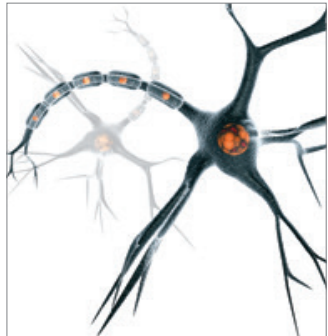

Neural Plasticity
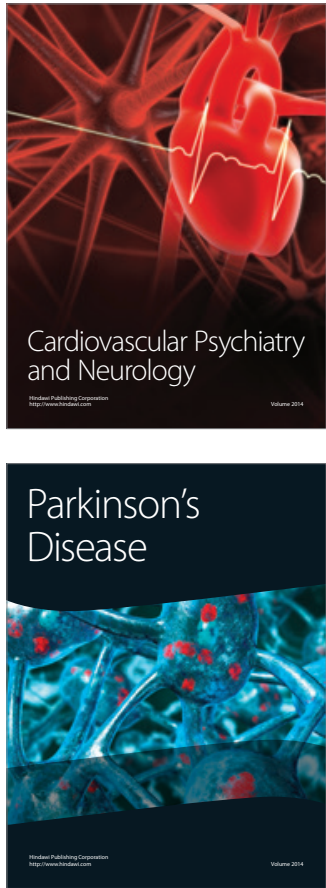